\title{
On the separation between inorganic and organic fractions of suspended matter in a marine coastal environment
}

\author{
M. Schartau ${ }^{\mathrm{a}, *}$, R. Riethmüller ${ }^{\mathrm{b}, * *}$, G. Flöser ${ }^{\mathrm{b}}$, J. E. E. van Beusekom ${ }^{\mathrm{b}}$, \\ H. Krasemann ${ }^{\mathrm{b}}$, R. Hofmeister ${ }^{\mathrm{b}}, \mathrm{K}$. Wirtz ${ }^{\mathrm{b}}$ \\ ${ }^{a}$ GEOMAR Helmholtz Centre for Ocean Research Kiel \\ ${ }^{b}$ Helmholtz-Zentrum Geesthacht, Centre for Materials and Coastal Research
}

\begin{abstract}
A central aspect of coastal biogeochemistry is to determine how nutrients, lithogenicand organic matter are distributed and transformed within coastal and estuarine environments. Analyses of the spatio-temporal changes of total suspended matter (TSM) concentration indicate strong and variable linkages between intertidal fringes and pelagic regions. In particular, knowledge about the organic fraction of TSM provides insight to how biogenic and lithogenic particulate matter are distributed in suspension. In our study we take advantage of a set of over 3000 in situ Loss on Ignition (LoI) data from the Southern North Sea that represent fractions of particulate organic matter (POM) relative to TSM (LoI $\equiv$ POM:TSM). We introduce a parameterization (POM-TSM model) that distinguishes between two POM fractions incorporated in TSM. One fraction is described in association with mineral particles. The other represents a seasonally varying fresh pool of POM. The performance of the POM-TSM model is tested against data derived from MERIS/ENVISAT-TSM products of the German Bight. Our analysis of remote sensing data exhibits specific qualitative features of TSM that can be attributed to distinct coastal zones. Most interestingly, a transition zone between the Wadden Sea and seasonally stratified regions of the Southern North Sea is identified where mineral associated POM appears in concentrations comparable to those of freshly produced POM. We will discuss how this transition is indicative for a zone of effective particle interaction and sedimentation. The dimension of this transition zone varies between seasons and with location. Our proposed POM-TSM model is generic and can be calibrated against in situ data of other coastal regions.
\end{abstract}

Keywords: Total suspended matter (TSM), Loss on Ignition, Particulate organic matter (POM), Particulate inorganic matter (PIM), Ocean color, Coastal biogeochemistry

\footnotetext{
*First corresponding author

** Second corresponding author

Email addresses: mschartau@geomar.de (M. Schartau), rolf.riethmueller@hzg.de (R. Riethmüller)
} 


\section{Highlights}

- Two types of organic matter inferred from total suspended matter concentration

- Organic matter is mainly mineral associated at high suspended matter concentrations

- Freshly produced organic matter dominates at low suspended matter concentrations

- Spatial patterns in organic matter types reveal coastal transition zones

- Specific zones for particle interaction and sedimentation can be identified

\section{1. Introduction}

Oceanographic observations of coastal- and shallow shelf regions often reveal 3 variability that is well pronounced on local and regional scales. In addition

4 to explaining the variability of the physical dynamics, it is also of interest

5 to understand changes in the biogeochemical characteristics of the coastal 6 waters (e.g. Kallis and Butler, 2001; Hering et al., 2010). Therefore, coastal 7 science is in many cases concerned with the quantitative and qualitative 8 determination of suspended matter (e.g. Eisma, 1981; Eisma and Irion, 9 1988). In literature the term "suspended matter" (e.g. Postma, 1981) is also 10 referred to as suspended particulate matter (SPM, e.g. Sundby, 1974), or 11 total suspended solids (TSS, e.g. Daphne et al., 2011). Many recent remote 12 sensing studies involve analyses of concentrations of total suspended matter 13 (TSM, e.g. Ouillon et al., 2008; Petus et al., 2010). Since the notion "TSM" 14 is clear and unambiguous we adopt this terminology for our study.

15 Changes in TSM concentrations are associated with the dispersion of 16 river loads, tidal transport, and resuspension of biogenic and lithogenic sed17 iments (Postma, 1954). On seasonal scale, variability in TSM is enhanced 18 due to the build-up and decay of organic matter. The relative amount of 
photoautotrophy (build-up of organic matter) versus heterotrophy (transformation and decay of organic matter) in coastal zones is sensitive to light availability (Cloern et al., 2014), which in turn depends on the TSM concentration. In this respect, analyses of the composition of TSM can provide important constraints for the estimation of mass exchange rates, e.g. of carbon, nitrogen, or phosphorus between shallow coastal zones and adjacent shelf regions (Meybeck, 1982; Sundby et al., 1992; Smith et al., 2001; Van Beusekom and De Jonge, 2002; Cloern et al., 2014). Regional gradients and patterns of quantitative and qualitative variations of TSM may disclose information about the concurrence of physical-, chemical- and biological processes that leave an imprint on mass flux, including sediment transport, long-term morphodynamics, and biogeochemistry.

Early mass flux and budget calculations of TSM have been done for the Gulf of St. Lawrence (Sundby, 1974), the North Sea (Postma, 1981; Eisma and Kalf, 1987; Eisma and Irion, 1988), or for the German Bight (Puls et al., 1997). In these studies the TSM's qualitative characteristics, e.g. grain-size, helped consolidating mass inventories. Likewise, origin and fate of matter in estuarine turbidity maximum zones can be better identified by measuring the quality of TSM, as done for example in the Humber-Ouse estuary (Uncles et al., 2006) or Elbe estuary (Van Beusekom and Brockmann, 1998). The portion of particulate organic matter (POM) of TSM is of particular interest, e.g. when investigating organic matter incorporation into sediments and its preservation therein (e.g. Keil et al., 1994; Mayer, 1994; Arnarson and Keil, 2001), or when analysing sorption of dissolved organic carbon (Middelburg and Herman, 2007) or of trace elements (Nyeffeler et al., 1984; Comber et al., 1996; Garnier et al., 2006) on particles.

The percentage of organic matter of TSM can be determined by a gravi- 
metric method, based on consecutive measurements of the particulate matter retained on individual filters. This method involves the combustion of organic matter and it is referred to as Loss-on-Ignition (LoI). For marine sediments, Wang et al. (2011) found that this method yields reliable results as long as certain temperature and duration ranges are obeyed and identical protocols in the lab procedures are followed. However, the chemical analyses of in situ TSM field samples is laborious, which demands a trade-off in sampling effort and thus in spatio-temporal resolution.

Horizontal spatial and temporal patterns of TSM can be well resolved from remote sensing, although cloud coverage impairs the availability of usable measurements. Also, the tidal dynamics remain largely unresolved (no more than two satellite overflights per day per region), and processes along the vertical such as mixing, settling, and resuspension may also be undetected. In spite of these limitations, remote sensing data are indispensable. Available remote sensing TSM data products typically represent a bulk quantitative measure, but it is desirable to obtain qualitative information from these products as well. During the past years, analyses of the waters' inherent optical properties (IOPs) have advanced the description of qualitative TSM characteristics in coastal areas (e.g. Babin and Stramski, 2004; Stavn and Richter, 2008; Martinez-Vicente et al., 2010; Zhang et al., 2014; Woźniak, 2014). Stavn and Richter (2008) proposed a discrimination between mass-specific scattering cross-sections that allows distinguishing between particulate inorganic matter (PIM) and POM. An alternative approach to analysing IOPs is to establish a mathematical relationship for the estimation of PIM and POM concentrations, based on in situ TSM and LoI field measurements.

The central idea of our study is to devise a generic model of the organic 
content as a function of TSM concentration (POM-TSM model). We take advantage of a large number of in situ LoI measurements collected in the southern North Sea, mainly within the German Bight. With these observations we derived a model that describes predominant changes seen in the LoI data. After calibration, the model can be applied to estimate POM from bulk TSM concentration measurements of those devices that do not detect POM explicitly, e.g. from in situ turbidity sensors or from remote sensing products. Such POM estimates can support analyses of fluorescence measurements and the POM-TSM model may also be used to complement analyses of IOPs. We treat the measured LoI as a mixed signal of two inherently different POM fractions, similar to distinctions proposed by Ittekkot (1988) for riverine particulate organic carbon (POC): one is associated with sediment minerals (e.g. Keil et al., 1994) and another is attributed to the seasonal build-up and decay of "fresh" organic biomass.

The proposed POM-TSM model is represented by a simple equation with two parameters. Maximum likelihood (ML) estimates of parameter values are determined by using data of specified periods, for Spring/bloom, Summer/post-bloom, and for Fall/winter respectively. We seek to make inference about the differences between optimal parameter estimates obtained for these seasons. The usability of the calibrated POM-TSM model is exemplified by applying it to remote sensing data of TSM concentration in the German Bight for the years 2010 and 2011 (2008 and 2009 are available as supplemental material). We will discuss the mixing model of Morris et al. (1987); an approach that has often been used to describe the POC fraction of TSM. Potential improvements of our static POM-TSM model will be elucidated, while discussing how temporal and spatial variations of the model's parameter values can be accounted for. 


\section{Methods}

\subsection{TSM concentration and Loss on Ignition (LoI) from water samples}

The water sample data $(\mathrm{N}=3600)$ considered here are publicly available in the World Data Center PANGAEA (https://pangaea.de/) (Riethmüller and Flöser, 2017), including a detailed documentation of the sampling and filtering methods. The available full data set also comprises measurements of the MaBenE project (Herman, 2006) from locations in the Oosterscheldt, Limfjorden, and Ria de Vigo $(\mathrm{N}=225)$. These MaBenE data were excluded and we used only those samples that were taken during numerous field surveys between the years 2000 and 2015 in several parts of the German Wadden Sea, the Exclusive Economic Zone of Germany in the German Bight, southern North Sea (Fig.1). This gives us a total of $\mathrm{N}=3375$ water samples for calibrations and analyses. The MaBenE measurements are considered for our discussion of the POM-TSM model's portability. The sampling areas and the number of samples per area are listed in Table 1. Over the years, the laboratory methods and the type of filter (Whatman GF/C glass fibre filter, $47 \mathrm{~mm}$ diameter) were kept identical, but the sampling methods were adapted to technical demands, to the specific conditions of the sampling areas.

About 800 samples (24\% of all data) before June 2003 were taken with a suction bottle sampler. From then onwards, the vast majority (62\%) of samples was taken by an on-board pump. In both cases, a sample bottle was filled with about $1 \mathrm{dm}^{3}$ in 30 seconds. 260 samples in the Wadden Sea were taken with an automated pump system installed on a permanent measuring station. About 400 samples collected in the German Bight were taken using a suction system by means of a motor controlled plunger with a filling time 
of 1 minute for $2 \mathrm{dm}^{3}$ of water. To assure the homogeneity of the overall data set, parallel sampling with the different methods was carried out. No systematic differences in the relation of LoI to TSM were detected. Overall, the sampling heights ranged from $1 \mathrm{~m}$ below surface to $1 \mathrm{~m}$ above seabed. Further details about sampling and lab methods are given in Riethmüller and Flöser (2017).

For each sample, TSM concentration and LoI were determined using the same filter. Prior to sampling, the filters were flushed with deionized water, heated to $525^{\circ}$ Celsius for one hour in a muffle furnace and weighed (filter dry weight). Vacuum filtration was carried out within 2 hours after

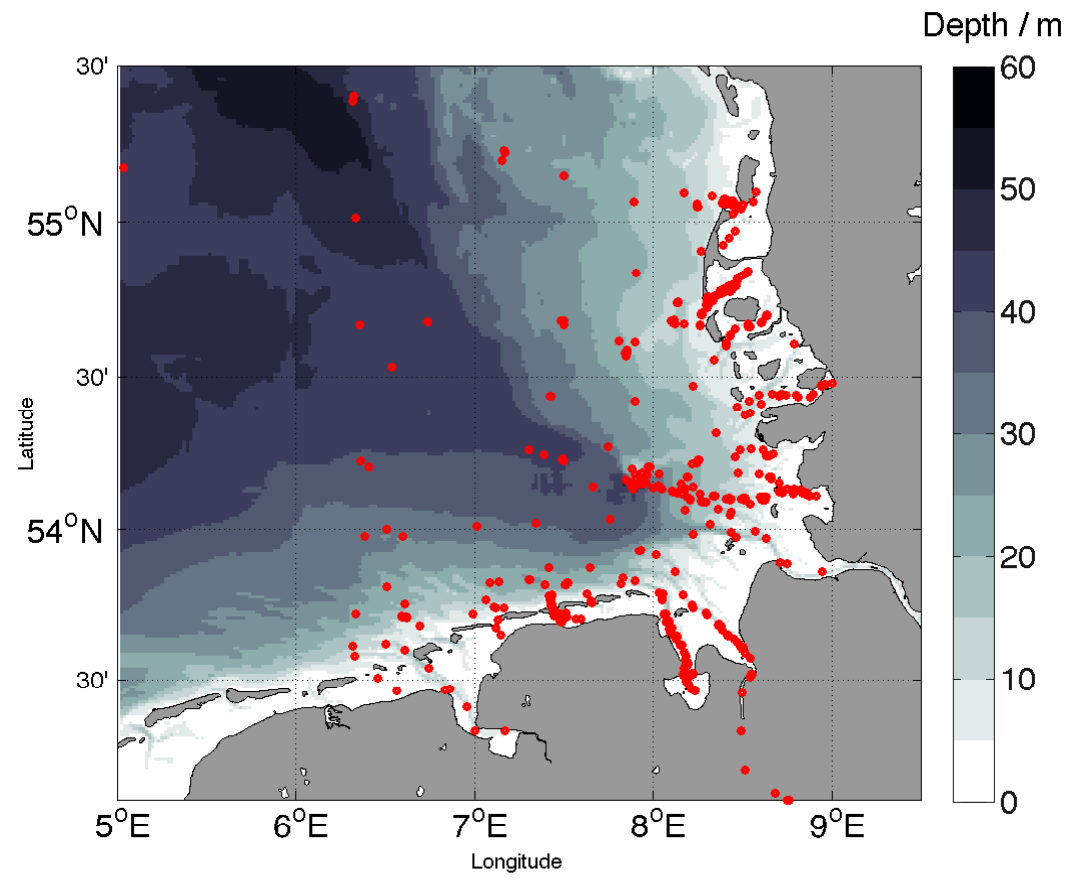

Figure 1: Bathymetry of the south-eastern part of the North Sea and locations of in situ TSM and LoI measurements in the German Bight (marked red). Depths are given in meters with respect to Normal Chart Datum. 
Table 1: Regions and number of available samples of Loss on Ignition (LoI) and total suspended matter (TSM) concentration measurements, as used for our analyses. See Figure 1 for the exact locations of sampling.

\begin{tabular}{ll} 
Region & Number of samples \\
\hline East Frisian Wadden Sea & 1195 \\
North Frisian Wadden Sea & 1536 \\
Estuaries Weser, Ems, Elbe & 96 \\
German Bight & 548 \\
\hline
\end{tabular}

All 3375

sampling and the filters were frozen immediately after filtering down to $-18^{\circ}$ Celsius until laboratory analysis. In cases of expected long filtration times (> $4 \mathrm{~h}$ per filter) at higher TSM concentrations (typically above $50 \mathrm{~g} \mathrm{~m}^{-3}$ ) and/or clogging of filters by fine suspended particles, the sampled water was filtered through two to four parallel filters, keeping the filtering times within reasonable limits. For the same reason, at very high TSM concentrations (typically above $100 \mathrm{~g} \mathrm{~m}^{-3}$ ) only representative subsamples of the collected water were filtered. In this case, the full sample was divided into halves or two times into quarters by pouring the gently rotated water bottle into a filter hopper with four outlets at the bottom, thus filling two bottles from each two opposite outlets. After filtering the sea water sample, the loaded filters were flushed with $120 \mathrm{~cm}^{3}$ of deionized water to remove the remaining salt from the filter. For determination of the TSM concentration, the loaded filters were dried in a microwave oven for 60 minutes and weighed afterwards. For LoI determination the loaded filters were heated to $525^{\circ}$ Celsius for one hour in a muffle furnace again. Following the protocol of Wang et al. (2011), 
nearly all organic carbon was burned while the loss of carbon from volatile inorganic compounds is minimized. However, the combustion duration was shorter than recommended by Wang et al. (2011), which may have created some small negative bias in the LoI. At the same time, this effect was found to be reproducible as long as identical protocols are followed. Eventually, the combusted filters are weighed again. Röttgers et al. (2014) have recently shown that significant and contradictory bias errors may still remain despite washing with deionized water, due to filter material loss during washing and combustion procedures. To determine the net loaded filter weight offsets on an individual sample basis they proposed filtering several different subvolumes of the same sample. As this method was not applied to all samples presented here, a statistical overall correction was assigned to filter weights. Since Röttgers et al. (2014) used Whatman GF/F glass-fibre filters in their investigations, we repeated the determination of filter offsets for $\mathrm{GF} / \mathrm{C}$ filters, with additional 30 water samples where four sub-volumes were filtered, following the procedures described therein. The average offset for loaded filters was $0.22 \mathrm{mg}$ (standard deviation $0.38 \mathrm{mg}$ ) and for combusted filters $0.47 \mathrm{mg}$ (standard deviation $0.22 \mathrm{mg}$ ). TSM concentration and LoI 
were defined and calculated according to the following formulae:

$$
\mathrm{TSM}=\frac{\sum_{i=1}^{N_{f}}\left(F_{\text {loaded }}-F_{\text {empty }}\right)_{i}-N_{f} \cdot F_{\text {corrL }}}{\sum_{i=1}^{N_{f}}\left(V_{\text {filtered }}\right)_{i}}
$$

and

$$
\mathrm{LoI} \equiv \frac{\sum_{i=1}^{N_{f}}\left(F_{\text {loaded }}-F_{\text {combusted }}\right)_{i}-N_{f} \cdot F_{\text {corrC }}}{\sum_{i=1}^{N_{f}}\left(F_{\text {loaded }}-F_{\text {empty }}\right)_{i}}(\cdot 100[\%])
$$

where $N_{f}$ is the number of filters per sample, $F_{\text {empty }}$ the dried empty filter weight, $F_{\text {loaded }}$ the dried loaded filter weight, $F_{\text {corrL }}$ the average dried loaded filter offset, $V_{\text {filtered }}$ the filtered sample volume, $F_{\text {combusted }}$ the combusted filter weight, and $F_{\text {corrC }}$ the average combusted filter offset. This correction reduces TSM concentrations typically by $0.3 \mathrm{~g} \mathrm{~m}^{-3}$ at $3 \mathrm{~g} \mathrm{~m}^{-3}$ and $0.4 \mathrm{~g}$ $\mathrm{m}^{-3}$ at $30 \mathrm{~g} \mathrm{~m}^{-3}$.

Finally, the bias introduced by loss of structural water was corrected according to Barillé-Boyer et al. (2003). Their formula requires the clay content and clay composition of the suspended particles. For the German Bight, Wadden Sea, Elbe and Weser estuaries these have been taken from data collected by Irion and Zöllmer (1999). The correction lowers the measured LoI. It increases with the inorganic fraction of the suspended particles, i.e. generally with the TSM concentration and amounts to $3 \%$ at TSM concentration of $3 \mathrm{~g} \mathrm{~m}^{-3}$ and $13 \%$ at $30 \mathrm{~g} \mathrm{~m}^{-3}$. For the other sampling areas, comparable data were not available. As this correction is minor and reveals only a weak dependency on the clay composition, all samples have been corrected with the parameters obtained from the German Bight samples. 
Each sample had to pass four tests before it was accepted for the analysis: i) the sampler did not touch the ground before sampling, ii) no loss of water during filtering, iii) the sampling location had to be at a clear distance from dump sites, iv) the filter weights had to be consistent, thereby rejecting cases of incorrectly transcribed filter weights. For each sample, the final methodological error in TSM concentration and LoI was individually computed applying Gaussian error propagation to Eq.(2). These calculations include the weighing errors and uncertainties in the respective offsets of the dried and burned loaded filters. Samples with TSM concentrations above $50 \mathrm{~g} \mathrm{~m}^{-3}$ yield relative errors for TSM in the order of $1 \%$. Concentrations below $50 \mathrm{~g} \mathrm{~m}^{-3}$ result in relative errors that gradually approach $15 \%$ with decreasing TSM concentration. For LoI, the errors depend on the TSM concentration as well as on the LoI: for TSM concentrations above $50 \mathrm{~g} \mathrm{~m}^{-3}$, the LoI relative error is below $1 \%$, at $3 \mathrm{~g} \mathrm{~m}^{-3}$, the error ranges between 2 and $6 \%$ with decreasing TSM concentration.

For our analysis we sorted all our German Bight/Wadden Sea in situ measurements $\left(\mathrm{N}_{\text {all }}=3375\right)$ according to distinct periods of the year. This way we obtained three different seasonal data subsets: a) Fall/winter/prebloom (October through March, $\mathrm{N}_{w}=727$ ), b) Spring/bloom (April through June, $\mathrm{N}_{b}=1346$ ), and c) Summer/post-bloom (July through September, $\mathrm{N}_{s}=1302$ ). Fig.2 shows all data subsets of LoI measurements versus TSM concentration. Probability density estimates of the seasonal data subsets were calculated with a bootstrap procedure (taking 100 subsamples from every data subset). The corresponding ensembles of empirical cumulative probability density estimates are used to evaluate differences between the seasonal data subsets, shown as subplot in Fig.2. 


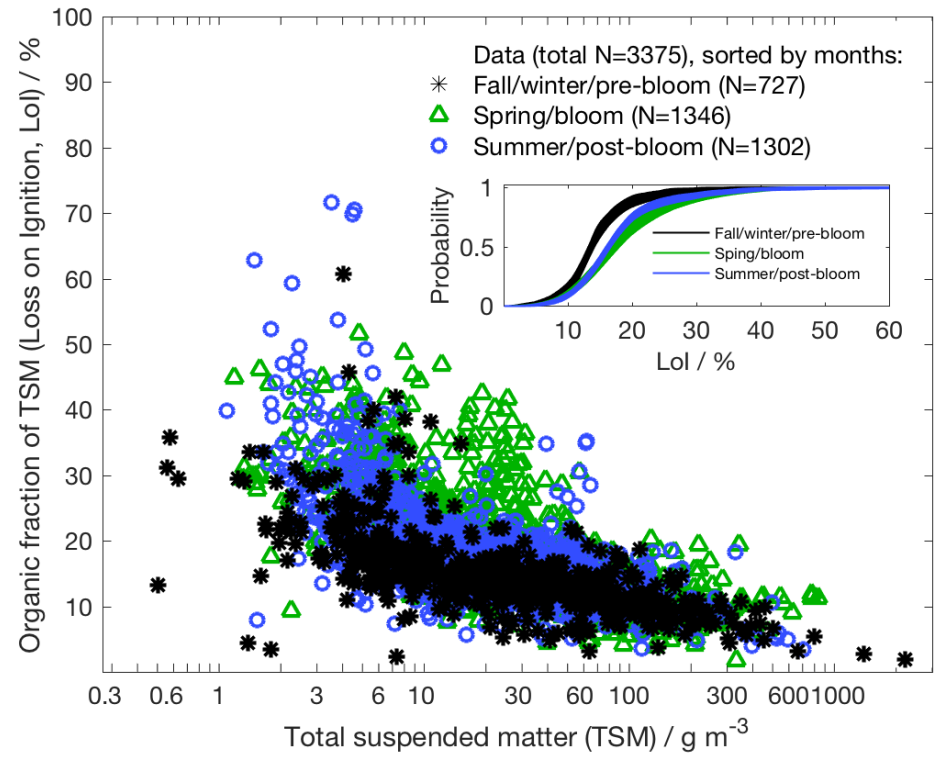

Figure 2: Organic fraction of total suspended matter (TSM), based on Loss on Ignition measurements ( $\mathrm{LoI}_{\mathrm{obs}}$ ), versus the corresponding TSM concentration. All data are sorted according to seasonal periods: a) Fall/winter/pre-bloom (October through March, black asterisks), b) Spring/bloom (April through June, green triangles), and c) Summer/post-bloom (July through September, blue circles). The subplot depicts empirical cumulative probability density functions (bootstrapped by taking 100 subsamples), showing the statistical differences between the seasonally sorted data sets.

\subsection{Remote sensing data of TSM concentration}

The remote sensing data of TSM concentrations were derived from measurements by MERIS (Medium Resolution Imaging Spectrometer) on ENVISAT, the Environmental Satellite of the European Space Agency. ENVISAT was in operation from the year 2002 until May in 2012. The MERIS is a passive push broom spectrometer of the full spectrum from violet to near infrared, with available spectral channels that are well suited for analysing coastal waters. In this study, reflectances and water constituents were derived with 
the algorithms MEGS 8.1 (equivalent to the IPF 6.04, Instrument Processing Facility), which are equivalent to MERIS 3rd reprocessing. For coastal waters a specific processing branch is applied, according to Doerffer and Schiller (2007) and Doerffer (2011), namely the C2R (Case-2 Regional processor, version $1.6 .2,2010)$ with a coupled atmospheric correction and in water constituent retrieval procedure for Case- 2 water, see Appendix A1 for more details.

We collected all available MERIS scenes over the North Sea. Individual pixels to which TSM concentrations could be assigned indicate a valid processing. However, for our study here we excluded those pixels from the analyses where the water column is shallower than 5 meters in depth to avoid effects from bottom reflectance that are not taken into account by the algorithm. We sorted processed scenes by months for the years 2008 through 2011, having typically around twenty scenes available for individual months. For each month we calculated mean TSM concentrations for those pixels that have at least four values assigned (no clouds) within the respective month. Although available, all scenes from November through February have been excluded from our analysis. The low inclination of the solar irradiance at these latitudes during winter in combination with very low TSM concentrations within the deeper pelagic regions enhance uncertainties in resolving coherent spatial patterns, from the shallow coastal zones to the deeper areas of the German Bight. In the end we analysed mean TSM scenes for the months March through October, from 2008 through 2011. 


\section{Theory}

A LoI value expresses the relative fraction of POM for a corresponding measured TSM concentration (LoI $\equiv$ POM:TSM). Fig.2 reveals a sigmoidal increase in LoI measurements with decreasing TSM concentration. Most of our data of the German Bight exhibit TSM concentrations above $1 \mathrm{~g} \mathrm{~m}^{-3}$, with only four winter measurements where TSM varies between 0.5 and 1 $\mathrm{g} \mathrm{m}^{-3}$. Our LoI data typically approach maximum values between 0.5 and 0.7 (50 and $70 \%)$ at the low range of TSM concentrations $\left(<5 \mathrm{~g} \mathrm{~m}^{-3}\right)$. LoI shows little variations at high TSM concentrations $\left(>200 \mathrm{~g} \mathrm{~m}^{-3}\right)$, indicating a prevailing organic fraction between 3 and $13 \%$. The transition from low to high organic fractions of TSM or of the respective organic carbon content is a robust qualitative feature that has been observed in many studies in the past within different coastal, estuary and riverine regions (e.g. Manheim et al., 1972; Eisma and Kalf, 1987; Ittekkot and Laane, 1991). Motivated by these characteristics, we devised a relationship between LoI and TSM concentration (POM-TSM model), which will be explained stepwise.

\subsection{Differentiation between particulate inorganic- and organic suspended} matter

TSM can be partitioned into particulate inorganic matter (PIM) and particluate organic matter (POM):

$$
\mathrm{TSM}=\mathrm{PIM}+\mathrm{POM}
$$

Each of the two major fractions (PIM and POM) can be split up further, as described in the following. 


\subsubsection{Lithogenic and biogenic particulate inorganic matter}

PIM in coastal sea regions consists of lithogenic particles $\left(\mathrm{PIM}_{l}\right)$ and biogenic particles $\left(\mathrm{PIM}_{b}\right) . \quad \mathrm{PIM}_{l}$ mainly originates from local sediment resuspension or may have been advected from other sources (e.g. rivers). $\mathrm{PIM}_{b}$ may contain locally produced biominerals like opal (from diatoms, silicoflagellates), calcium-carbonate (e.g. from coccolithophorids) or resuspended biominerals like fragmented carbonate shells of benthic molluscs. For our study we do not separate between $\mathrm{PIM}_{l}$ and $\mathrm{PIM}_{b}$ and only consider a single pool of total PIM $\left(\mathrm{PIM}_{l}+\mathrm{PIM}_{b}\right)$.

\subsubsection{Differentiation between two types of particulate organic matter (POM)} The POM holds a mixture of various organic matter types whose dynamics are subject to formation and degradation processes on different time scales. Sediments incorporate organic substances that are chemically bound to lithogenic minerals (e.g. Arnarson and Keil, 2007), and that are slowly or hardly hydrolized by bacterial enzymes. A fraction of this sediment associated organic matter can be a mixture of bacteria, fragmented detrital matter, gel-like organic particles, but also microphytobenthos. We hereafter refer to this fraction as mineral associated $\mathrm{POM}\left(\mathrm{POM}_{m}\right)$. The $\mathrm{POM}_{m}$ is assumed to be more refractory than the complementary POM fraction that is formed and degraded on a time scale of days to weeks, here referred to as fresh $\mathrm{POM}\left(\mathrm{POM}_{f}\right) \cdot \mathrm{POM}_{f}$ is assumed to primarily depend on the seasonal build-up and degradation of plankton biomass, including algae, zooplankton and detritus. In the end we discriminate between two types of POM:

$$
\mathrm{POM}=\mathrm{POM}_{f}+\mathrm{POM}_{m}
$$


In the following we will resort to $\mathrm{PIM}, \mathrm{POM}_{m}$, and $\mathrm{POM}_{f}$ for deriving a mathematical relationship between POM and TSM concentration, which constitutes our POM-TSM model.

\subsubsection{Definition of mineral associated particulate organic matter $\left(P O M_{m}\right)$} According to our definition, we assume $\mathrm{POM}_{m}$ to be largely accompanied with the resuspension of PIM. We therefore introduce a linear relationship between $\mathrm{POM}_{m}$ and PIM in the water column, with a constant $m_{\mathrm{POM}}$ being the proportionality factor. The parameter $m_{\mathrm{POM}}$ thus specifies the amount of suspended $\mathrm{POM}_{m}$ along with the resuspension of PIM:

$$
\mathrm{POM}=\mathrm{POM}_{f}+\mathrm{POM}_{m}=\mathrm{POM}_{f}+m_{\mathrm{POM}} \cdot \mathrm{PIM}
$$

The PIM itself is (1-LoI) multiplied with the TSM concentration, and with $m_{\mathrm{POM}}$ as our first parameter, the LoI measurements can be interpreted as:

$$
\begin{aligned}
\mathrm{LoI} & =\frac{\mathrm{POM}}{\mathrm{TSM}}=\frac{\mathrm{POM}_{f}+m_{\mathrm{POM}} \cdot \mathrm{PIM}}{\mathrm{TSM}} \\
& =\frac{\mathrm{POM}_{f}+m_{\mathrm{POM}} \cdot(1-\mathrm{LoI}) \cdot \mathrm{TSM}}{\mathrm{TSM}}
\end{aligned}
$$

Since $\mathrm{POM}_{m}$ is assumed to become hydrolised slowly we expect variations in $m_{\mathrm{POM}}$ mainly because of differences between sediment types, depending on how much of the organic matter can be incorporated into sediments (Flemming and Delafontaine, 2000).

We may solve Eq.(6) for LoI, emphasizing the mixed contribution of two terms: one that explains variations of LoI according to fresh $\mathrm{POM}_{f}$ and another that determines the amount of sediment associated $\mathrm{POM}_{m}$. The latter is entirely specified by the parameter $m_{\mathrm{POM}}$ :

$$
\mathrm{LoI}=\frac{\mathrm{POM}_{f}}{\mathrm{TSM}} \cdot \frac{1}{m_{\mathrm{POM}}+1}+\frac{m_{\mathrm{POM}}}{m_{\mathrm{POM}}+1}
$$


For Eq.(7) we still require a proxy for $\mathrm{POM}_{f}$, which has to be defined in addition.

\subsubsection{Definition of fresh particulate organic matter $\left(P O M_{f}\right)$}

The $\mathrm{POM}_{f}$ consists of "freshly" built up photoautrophs, mixotrophs, but also of heterotrophic organisms, and of detritus. For a parameterization of $\mathrm{POM}_{f}$ as a function of TSM we assume the existence of an upper concentration limit, i.e. a maximum amount of $\mathrm{POM}_{f}$ that could possibly accumulate. Naturally, such upper limit depends on the regional availability of nutrients. We therefore describe $\mathrm{POM}_{f}$ as a saturation function of TSM:

$$
\mathrm{POM}_{f}=\frac{K_{\mathrm{POM}}}{\frac{K_{\mathrm{POM}}}{\mathrm{TSM}}+1}
$$

with $K_{\mathrm{POM}}$ (in same units as TSM concentration) as a second parameter for the LoI parameterization. By definition the $\mathrm{POM}_{f}$ concentration never exceeds that of TSM. At some high TSM concentration the $\mathrm{POM}_{f}$ concentration does not raise any further, with the consequence of the $\mathrm{POM}_{f}$ 's weight proportion continuously decreases with increasing TSM concentration. According to Eq.(8) we do not distinguish between fresh organic matter that is kept in suspension all the time and "fresh" organic matter resuspended from fluffy layers on top of the sediments. Unlike $m_{\mathrm{POM}}$, the second parameter $K_{\mathrm{POM}}$ is expected to be time-variant on time scales of the build-up and decay of organic mass. Estimates of $K_{\mathrm{POM}}$ are thus a measure of the net accumulation of $\mathrm{POM}_{f}$. In Eq.(8) the value of $K_{\mathrm{POM}}$ determines the TSM concentrations at which the $\mathrm{POM}_{f}$ :TSM ratio becomes $0.5(50 \%)$ :

$$
\frac{\mathrm{POM}_{f}}{\mathrm{TSM}}=\frac{\frac{K_{\mathrm{POM}}}{\mathrm{TSM}}}{\frac{K_{\mathrm{POM}}}{\mathrm{TSM}}+1}=0.5 \text { at } \mathrm{TSM}=K_{\mathrm{POM}}
$$

Note that this does not imply that LoI in Eq.(7) becomes 0.5 when TSM = $K_{\mathrm{POM}}$, unless we assume the absence of $\mathrm{POM}_{m}$ while setting the parameter 
332

$m_{\mathrm{POM}}$ to zero.

3.1.5. LoI as a function of TSM and the parameters $m_{P O M}$ and $K_{P O M}$ With two parameters, $m_{\mathrm{POM}}$ and $K_{\mathrm{POM}}$ respectively, we can describe a non-linear dependency between LoI and TSM concentration by combining Eqs.(7) and (8). The estimation of LoI as a function of TSM can finally be written as:

$$
\begin{aligned}
\mathrm{LoI} & =\left(\frac{\frac{K_{\mathrm{POM}}}{\mathrm{TSM}}}{\frac{K_{\mathrm{POM}}}{\mathrm{TSM}}+1}\right) \cdot \frac{1}{\left(m_{\mathrm{POM}}+1\right)}+\frac{m_{\mathrm{POM}}}{\left(m_{\mathrm{POM}}+1\right)} \\
& =\frac{K_{\mathrm{POM}} \cdot\left(m_{\mathrm{POM}}+1\right)+m_{\mathrm{POM}} \cdot \mathrm{TSM}}{\left(K_{\mathrm{POM}}+\mathrm{TSM}\right) \cdot\left(m_{\mathrm{POM}}+1\right)}
\end{aligned}
$$

The above derived dependency between LoI and TSM complies with some meaningful and desired convergence characteristics. For TSM concentrations that approach inifinity, Eq.(10) converges to a constant value:

$$
\lim _{\mathrm{TSM} \rightarrow \infty} \operatorname{LoI}=\frac{m_{\mathrm{POM}}}{m_{\mathrm{POM}}+1}
$$

and LoI converges to one for TSM concentrations approaching zero, provided that $K_{\mathrm{POM}}>0 \mathrm{~g} \mathrm{~m}^{-3}$ :

$$
\lim _{\mathrm{TSM} \rightarrow 0} \mathrm{LoI}=1 \quad(100 \% \text { or } \mathrm{TSM}=\mathrm{POM})
$$

The solutions of the POM-TSM model, Eq.(10), can be calibrated with LoI measurements. Credible values of $m_{\mathrm{POM}}$ and $K_{\mathrm{POM}}$ can be retrieved by e.g. a maximum likelihood estimation (MLE), as described in the following.

\subsection{Data sorting and error assumptions for parameter optimization}

For the MLE of parameter values for $m_{\mathrm{POM}}$ and $K_{\mathrm{POM}}$ we assume all LoI data to be independent. No prior information about $m_{\mathrm{POM}}$ and $K_{\mathrm{POM}}$ is 
introduced other than imposing upper and lower limits of feasible values, 0 and $5 \mathrm{~g} \mathrm{~m}^{-3}$ for $K_{\mathrm{POM}}$, and 0 and 0.5 for $m_{\mathrm{POM}}$. The likelihood is a conditional probability that, in our case, is assumed to follow a Gaussian error distribution to describe deviations between results of the POM-TSM model $(\widehat{\mathrm{LoI}}=\mathrm{LoI} \cdot 100 \%)$ and the data $\left(\mathrm{LoI}_{\mathrm{obs}}\right)$. As to the convenience, instead of maximizing the likelihood, we calculate and minimize the likelihood's negative logarithm:

$$
-\ln (L)=\sum_{i}^{N}-\ln \left(\frac{1}{\sigma_{i} \sqrt{2 \pi}}\right)+\sum_{i}^{N}\left(\frac{\mathrm{LoI}_{\mathrm{obs}}-\widehat{\mathrm{LoI}}}{2 \sigma_{i}}\right)_{i}^{2}
$$

The minimum of the negative logarithm of the likelihood represents a best fit of the POM-TSM model results to the $\mathrm{N}$ measurements of LoI, each data point respectively indexed with $i$. The first term of Eq.(13) does not depend on the POM-TSM model output and is insensitive to parameter variation. For MLE we may therefore minimize only the second term of Eq.(13). Uncertainties of parameter estimates (standard deviations, $\sigma_{K}$ and $\left.\sigma_{s}\right)$ are calculated as square roots of the inverse of second derivatives of the negative log-likelihood with respect to each parameter.

Variations in the LoI data (variances $\sigma_{i}^{2}$ ) involve individual uncertainties in the measurement procedure (methodological error, $\sigma_{\text {method }}^{2}$ ). But we also find substantial variability in LoI due to variations between water samples that were taken at similar times at neighbouring locations, which can be attributed to heterogeneity (patchiness) in the organic content of TSM. Accounting only for the methodological error for MLE is problematic, because the parameter estimates can become overly sensitive to the number and spread of LoI measurements at high TSM concentrations. This is because the methodological errors of the LoI measurements are very low for TSM concentrations above approximately $100 \mathrm{~g} \mathrm{~m}^{-3}$ and these errors do not cover 
variability in LoI due to patchiness $\left(\sigma_{\mathrm{SV}}\right)$.

Prior to parameter optimization we apply an error model that estimates $\sigma_{\mathrm{SV}}$ as a function of TSM (details are given in Appendix B). Briefly, the data are first sorted (binned) into logarithmically scaled intervals. In a second step, standard deviations (total error) of LoI are computed for these intervals and the specific methodological errors are subtracted, which provides a first approximation of $\sigma_{\mathrm{SV}}$ for individual intervals. As a final step, the so derived errors are fitted by an error model that describes $\sigma_{\mathrm{SV}}$ as a function of TSM concentration, which is achieved by means of root mean square minimization (Fig.B.1). A major advantage of applying an error model is that the final estimates of $\sigma_{\mathrm{SV}}$ become much less sensitive to the chosen logarithmic width of the intervals.

Optimum parameter combinations of $m_{\mathrm{POM}}$ and $K_{\mathrm{POM}}$ are determined for seasonally sorted data sets (Fig.2) and for some unsorted set (where no seasonal periods have been specified). Each seasonal data set is then randomly split up further into a calibration subset used for parameter optimization (with $\mathrm{N}_{w 0}=364, \mathrm{~N}_{b 0}=673, \mathrm{~N}_{s 0}=651$, being $50 \%$ of $\mathrm{N}_{a}, \mathrm{~N}_{b}$, $\mathrm{N}_{c}$ respectively). The residual data (not used for calibration) are employed only for calculating error distributions of respective POM estimates. Finally, we retrieved parameter estimates for measurements of Hommersom et al. (2009). These additional independent data are used for comparison between the optimized parameter values. Their data are based on samples collected in the Wadden Sea, mainly between May and September in 2006 and again in May 2007. 


\section{Results}

\subsection{Parameter estimates of seasonally sorted data subsets of LoI}

For the parameter $K_{\mathrm{POM}}$ we find substantial variations between the different seasons (Table 2). The Fall/winter/pre-bloom data (October through March) exhibit an increase from approximately $10 \%$ to $30 \%$ in LoI at low TSM concentrations and the estimate of $K_{\mathrm{POM}}$ turns out to be the lowest accordingly $\left(0.52 \pm 0.07 \mathrm{~g} \mathrm{~m}^{-3}\right)$. From April to June the LoI data show great variability for TSM concentrations between 3 and $60 \mathrm{~g} \mathrm{~m}^{-3}$ while maxima in LoI exceed values observed during the other seasons clearly (Fig.3). Using the Spring/bloom data subset we obtain $K_{\mathrm{POM}}=1.42 \pm 0.10 \mathrm{~g} \mathrm{~m}^{-3}$. As a consequence of the high spatio-temporal variability during the bloom period we find some pronounced maxima in LoI measurements that remain unresolved by the POM-TSM model, mainly for TSM concentrations between 20 and $30 \mathrm{~g} \mathrm{~m}^{-3}$. In spite of the large spread in LoI data at similar TSM concentrations, the model solution for the Spring/bloom data is well constrained and LoI estimates are significantly higher then the corre-

Table 2: Maximum likelihood estimates of the POM-TSM model's parameters: a) based on three data subsets sorted by months of the year, b) based on unsorted data (no seasons resolved), c) based on data of the study of Hommersom et al. (2009).

\begin{tabular}{lll} 
Seasonal period & $K_{\mathrm{POM}} \pm \sigma_{K} /\left[\mathrm{g} \mathrm{m}^{-3}\right]$ & $m_{\mathrm{POM}} \pm \sigma_{s} /[]$ \\
\hline Fall/winter/pre-bloom (Oct. through Mar.) & $0.52 \pm 0.07$ & $0.122 \pm 0.004$ \\
Spring/bloom (Apr. through Jun.) & $1.42 \pm 0.10$ & $0.126 \pm 0.005$ \\
Summer/post-bloom (Jul. through Sept.) & $0.74 \pm 0.07$ & $0.140 \pm 0.004$ \\
\hline Fit to data with no period specified & $0.94 \pm 0.05$ & $0.128 \pm 0.003$ \\
Fit to data of Hommersom et al. (2009) & $3.00 \pm 0.48$ & $0.168 \pm 0.014$
\end{tabular}


sponding fall and winter values. For the Summer/post-bloom data set (July through September) we find LoI values to be lower than those found for the Spring/bloom data at TSM concentrations below $30 \mathrm{~g} \mathrm{~m}^{-3}$. The best summer estimate of $K_{\mathrm{POM}}$ becomes $0.74 \pm 0.07 \mathrm{~g} \mathrm{~m}^{-3}$, which is closer to the winter value than to the spring estimate. If all seasonal data are merged and used for optimization, the best value of $K_{\mathrm{POM}}$ turns out to be $0.94 \pm 0.05 \mathrm{~g}$ $\mathrm{m}^{-3}$. This estimate is slightly higher than $K_{\mathrm{POM}}$ for summer but it matches the average of the estimates obtained for the Spring/bloom and Fall/winter/pre-bloom data subsets. Optimal estimates of the proportionality factor for $\mathrm{POM}_{m}\left(m_{\mathrm{POM}}\right)$, which is associated with the mineral fraction, reveal little sensitivity to seasonal variations, ranging between $0.122 \pm 0.004$ and $0.140 \pm 0.004$. The estimates of $m_{\mathrm{POM}}$ are mainly constrained by LoI data for TSM concentrations above $50 \mathrm{~g} \mathrm{~m}^{-3}$. For these high TSM concentrations we find no clear differences between LoI data subsets of the different seasons (Figs.2 and 3). For comparison, we considered measurements of Hommersom et al. (2009) that were mainly collected in shallow water of the Wadden Sea during May and may thus be comparable with our POM-TSM model results calibrated with the Spring/bloom data subset. By fitting the POM-TSM model to data of Hommersom et al. (2009) we obtain higher LoI estimates, according to higher optimal values of $K_{\mathrm{POM}}=3.00 \pm 0.48 \mathrm{~g} \mathrm{~m}^{-3}$ and of $m_{\mathrm{POM}}=0.168 \pm 0.014$ (Table 2 ). The slightly higher estimates for $m_{\mathrm{POM}}$ can be explained with the presence of fluffy bottom layers of $\mathrm{POM}_{f}$ that may remain high in shallow waters even under conditions of extensive resuspension (with $\mathrm{TSM}>100 \mathrm{~g} \mathrm{~m}^{-3}$ ). Possible effects due to different measurement protocols will be discussed in Section (5.2.2). 


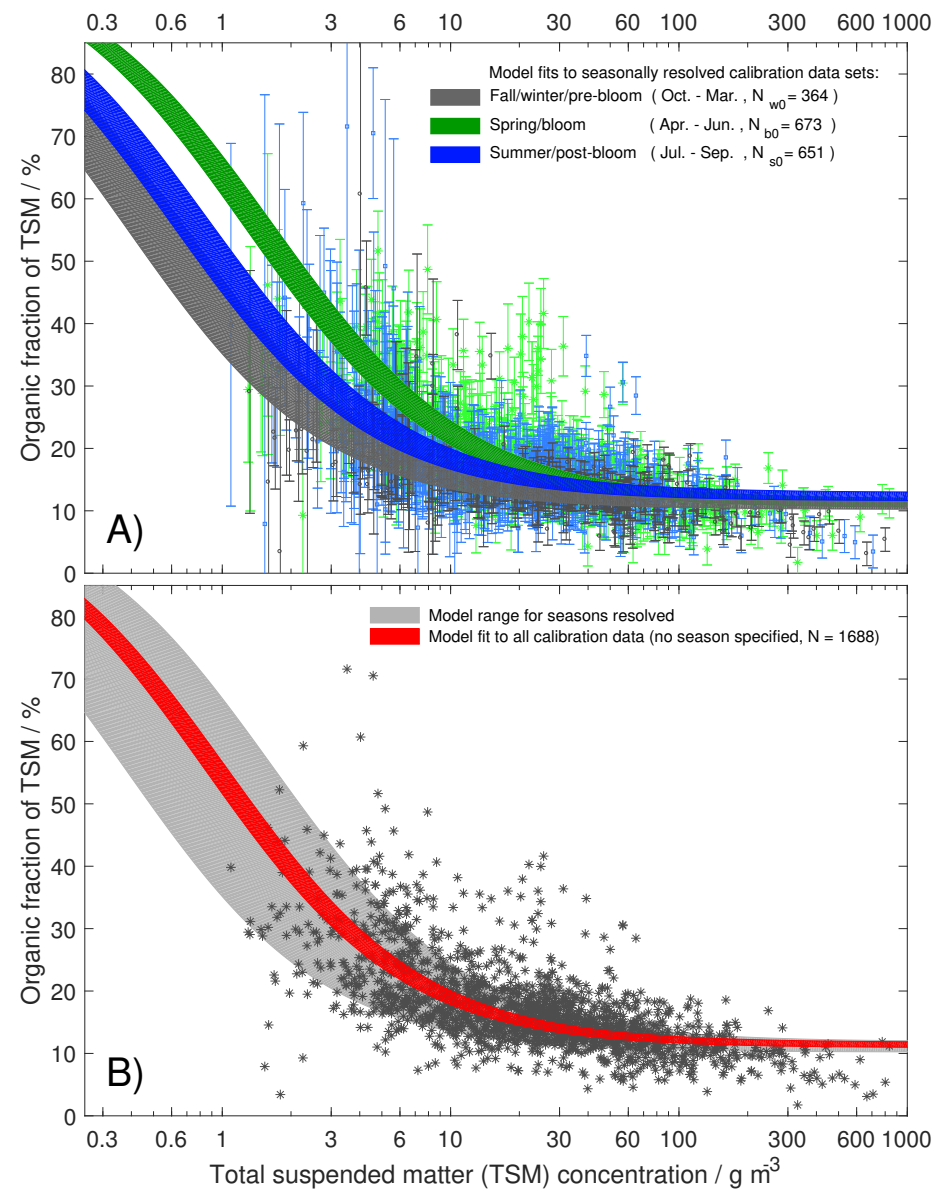

Figure 3: A) Seasonally resolved Loss on ignition data in $\%\left(\mathrm{LoI}_{\mathrm{obs}}\right)$ and results of the POM-TSM model ( $\widehat{\mathrm{LOI}})$. The error bars represent the individual uncertainties (standard deviations) of the LoI data, as described in Section 3.2. The spreads of model results correspond with uncertainties in the maximum likelihood estimates of the parameters: dark gray $=$ data and respective fit to the Fall/winter/pre-bloom period (Oct.-Mar., $K_{\mathrm{POM}}=0.52 \pm 0.07 \mathrm{~g} \mathrm{~m}^{-3}, m_{\mathrm{POM}}=0.122 \pm 0.004$ ); green $=$ Spring/bloom (Apr.-Jun., $K_{\mathrm{POM}}=1.42 \pm 0.10 \mathrm{~g} \mathrm{~m}^{-3}, m_{\mathrm{POM}}=0.126 \pm 0.005$ ); blue $=$ Summer/post-bloom (Jul.-Sep., $K_{\mathrm{POM}}=0.74 \pm 0.07 \mathrm{~g} \mathrm{~m}^{-3}, m_{\mathrm{POM}}=0.140 \pm$ 0.004). B) All LoI data used for calibration and the corresponding model fit (red, no season being specified), based on $K_{\mathrm{POM}}=0.94 \pm 0.05 \mathrm{~g} \mathrm{~m}^{-3}, m_{\mathrm{POM}}=0.128$ \pm 0.003 . The gray shaded areas is the envelope of all model fits to the seasonally resolved data subsets. 


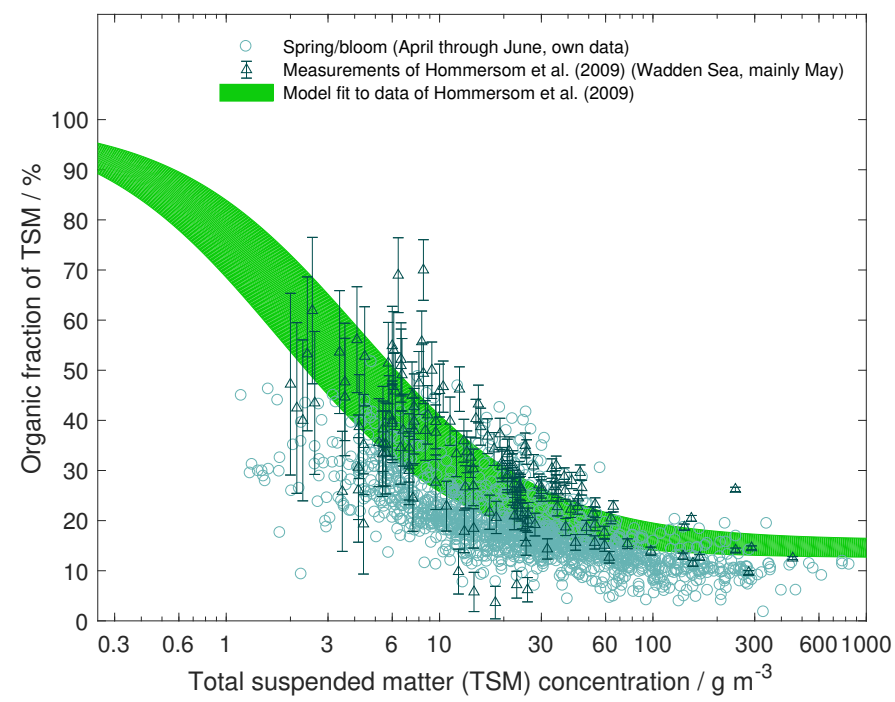

Figure 4: Comparison between the LoI fit to Wadden Sea data of Hommersom et al. (2009) (dark green triangles) and the corresponding fit of the POM-TSM model to these data (light green), with $K_{\mathrm{POM}}=3.00 \pm 0.48 \mathrm{~g} \mathrm{~m}^{-3}$ and $m_{\mathrm{POM}}=0.168 \pm$ 0.014. The spread of model results is associated with uncertainties in the parameter estimates. For comparison, the Spring/bloom data (dots) are added. 


\subsection{Model uncertainties in POM}

Errors of the POM-TSM model have been evaluated with the retained data that was not used for parameter optimization. Strictly speaking, the retained data subset may not be exclusively independent from the data used for calibration, as some of the divided (subsampled) data may include samples that were taken from joint locations at similar times and are thus correlated. However, the full data set exhibits substantial variability in TSM and LoI due to measurements from different years and from different sampling sites.

Fig.5 shows the cumulative probability distribution (CPD) of the residual errors in POM concentrations $\left(e^{\mathrm{res}}=\mathrm{POM}_{\mathrm{obs}}-\mathrm{POM}^{\text {model }}\right)$. The errors are given for two distinctive ranges of TSM concentrations, smaller and larger than $10 \mathrm{~g} \mathrm{~m}^{-3}$ respectively (Figs.5A and B). Residual errors are similar $\left(\left|e^{\text {res }}\right|<0.5 \mathrm{~g} \mathrm{~m}^{-3}\right.$ for TSM $<10 \mathrm{~g} \mathrm{~m}^{-3}$, Fig.5A) for all seasons. The cumulative error probability distributions (CPDs) are symmetric, with most modes $(\mathrm{CPD}=0.5)$ being nearly zero. Some bias exists for the spring/bloom period (green line in Fig.5A), where the POM-TSM model results of POM $\left(\mathrm{POM}^{\text {model }}\right)$ tend to overestimate the observed POM $\left(\mathrm{POM}_{\mathrm{obs}}=\mathrm{LoI}_{\mathrm{obs}} \times\right.$ $\left.\mathrm{TSM}_{\mathrm{obs}}\right)$. Although small, this bias can introduce limitations when estimating $\mathrm{POM}_{m}$ from POM measurements, which will be recalled in the following section.

For TSM larger than $10 \mathrm{~g} \mathrm{~m}^{-3}$ the uncertainties in POM increase, but with $\left|e^{\text {res }}\right|$ being smaller than $1 \mathrm{~g} \mathrm{~m}^{-3}$ for most of the data (Fig.5B). Here as well, the CPDs remain symmetric and the modes are close to zero. In contrast to the bias identified with our fit to the Spring/bloom data, we here find a tendency of the model to underestimate POM concentrations during the fall/winter period. In the end, this bias $\left(\approx 0.2 \mathrm{~g} \mathrm{~m}^{-3}\right)$ remains small 

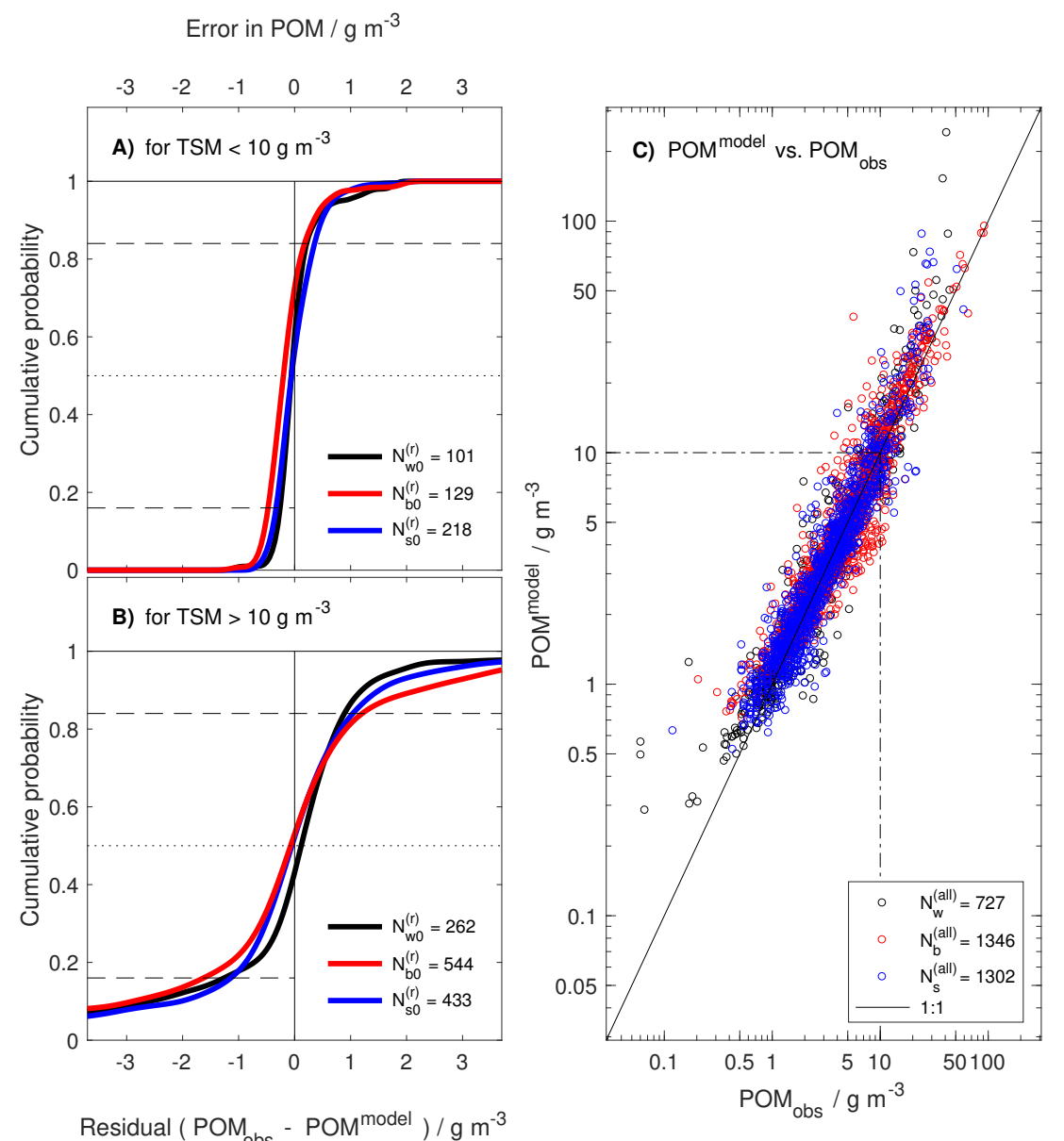

Figure 5: A) and B) show cumulative probability distributions (CPD) of the residual errors $\left(e^{\text {res }}=\mathrm{POM}_{\mathrm{obs}}-\mathrm{POM}^{\mathrm{model}}\right)$ in particulate organic matter $(\mathrm{POM})$, for total suspended matter (TSM) concentrations smaller and larger than $10 \mathrm{~g} \mathrm{~m}^{-3}$. Retained data sets (that had been excluded from model calibration) were used for the computations of the CPDs $($ Fall $/$ winter $/$ pre-bloom period $=$ black, Spring $/$ bloom $=$ red, Summer $/$ post-bloom $=$ blue $)$. All modes (median values where $\mathrm{CPD}=0.5$, dotted horizontal line) are close to zero (and $\left.\sum_{i} e_{i}^{\text {res }} \approx 0\right)$. Dashed lines enclose the $68 \%$ percentile $(0 \pm$ standard deviation $)$. C) shows a scatter plot of all estimated versus measured $\mathrm{POM}$ concentrations, $\mathrm{POM}^{\text {model }}$ and $\mathrm{POM}_{\text {obs }}$ respectively (same colour-code as in A and B). 
relative to those POM concentrations that correspond with TSM $>10 \mathrm{~g}$ $\mathrm{m}^{-3}$ (with POM typically ranging between 1 and $100 \mathrm{~g} \mathrm{~m}^{-3}$ ).

\subsection{Discrimination between $\mathrm{POM}_{f}$ and $\mathrm{POM}_{m}$}

With Eqs. (5) and (8) we introduced a discrimination between $\mathrm{POM}_{m}$ and $\mathrm{POM}_{f}$. Fig.6 highlights the model's applicability and limitation of separating $\mathrm{POM}_{m}$ and $\mathrm{POM}_{f}$ from observed POM concentrations (based on LoI measurements). The nonlinear dependency between concentrations of POM and TSM is evident from the observations and it is well resolved by estimates of the POM-TSM model, distinguished by the two periods (Fall/winter/prebloom and Spring/bloom) described before (Fig.6A). The nonlinearity becomes relevant mainly for TSM concentrations below $50 \mathrm{~g} \mathrm{~m}^{-3}$ whereas for higher TSM concentrations we find a nearly linear increase in POM with TSM concentration. At these high TSM concentrations the POM is dominated by mineral associated $\mathrm{POM}_{m}$. Estimates of $\mathrm{POM}_{f}$ and $\mathrm{POM}_{m}$ can both be individually derived, simply by subtracting either fractions obtained from the POM-TSM model from the measured POM.

Fig.6A shows estimates of $\mathrm{POM}_{m}\left(\mathrm{POM}_{m}^{\text {est }}\right)$ when subtracting model results of $\mathrm{POM}_{f}\left(\mathrm{POM}_{f}^{\text {model }}\right)$ from observed POM concentrations $\left(\mathrm{POM}_{\mathrm{obs}}\right.$ calculated as $\left.\mathrm{LoI}_{\mathrm{obs}} \cdot \mathrm{TSM}_{\mathrm{obs}}\right)$. Due to considerable scatter of data around the calibrated model results we may find conditions where $\mathrm{POM}_{f}^{\text {model }}$ can become larger than the observed $\mathrm{POM}_{\text {obs }}$ and thus $\mathrm{POM}_{m}^{\text {est }}$ becomes negative, which is the case for less than $3 \%$ of the data points used here. The bias mainly occurs in the Spring/bloom data subset (red markers in Fig.6A), where the POM-TSM model tends to overestimate the observed POM concentrations for TSM concentrations below $10 \mathrm{~g} \mathrm{~m}^{-3}$, as addressed before and seen in Fig.5C. For TSM concentrations above $10 \mathrm{~g} \mathrm{~m}^{-3}$ the model's $\mathrm{POM}_{m}$ 
results are in good agreement with the derived $\mathrm{POM}_{m}^{\mathrm{est}}$, thereby resolving the linear increase in $\mathrm{POM}_{m}$ with TSM concentration.

Like for $\mathrm{POM}_{m}^{\text {est }}$ we may approximate $\mathrm{POM}_{f}\left(\mathrm{POM}_{f}^{\text {est }}\right)$, this time subtracting model results of $\mathrm{POM}_{m}\left(\mathrm{POM}_{m}^{\text {model }}\right)$ from $\mathrm{POM}_{\mathrm{obs}}$ concentrations (Fig.6B). Variability in $\mathrm{POM}_{f}$ is well expressed, being much larger than in $\mathrm{POM}_{m}$. This can be explained by temporal variations, partially overlayed by differences between individual sampling sites (e.g. high LoI values in the Wadden Sea for Spring/bloom). Fig.6B depicts two special features. First, the $\mathrm{POM}_{f}$ increases with TSM concentration until it approaches an upper limit. Once these $\mathrm{POM}_{f}$ saturation concentrations are reached, it is the $\mathrm{POM}_{m}$ fraction that becomes the dominant contributor to total POM and any further increase in TSM concentration (e.g. by intensified resuspension) does not introduce additional $\mathrm{POM}_{f}$. Second, TSM concentrations at which $\mathrm{POM}_{f}$ and $\mathrm{POM}_{m}$ concentrations become equal (marked squares in Fig.6B) can vary between the seasons (e.g. 3 and $30 \mathrm{~g} \mathrm{~m}^{-3}$ between Fall/winter/prebloom and Spring/bloom). As for $\mathrm{POM}_{m}^{\text {est }}$ we could identify a model bias in $\mathrm{POM}_{f}^{\text {est }}$, but this time for TSM concentrations above $10 \mathrm{~g} \mathrm{~m}^{-3}$. The bias is introduced when $\mathrm{POM}_{m}^{\text {model }}$ concentrations exceed the observed POM, which happened for less than $18 \%$ of data in our case. We did not find a clear connection between these cases and the winter bias revealed in Fig.5B. 


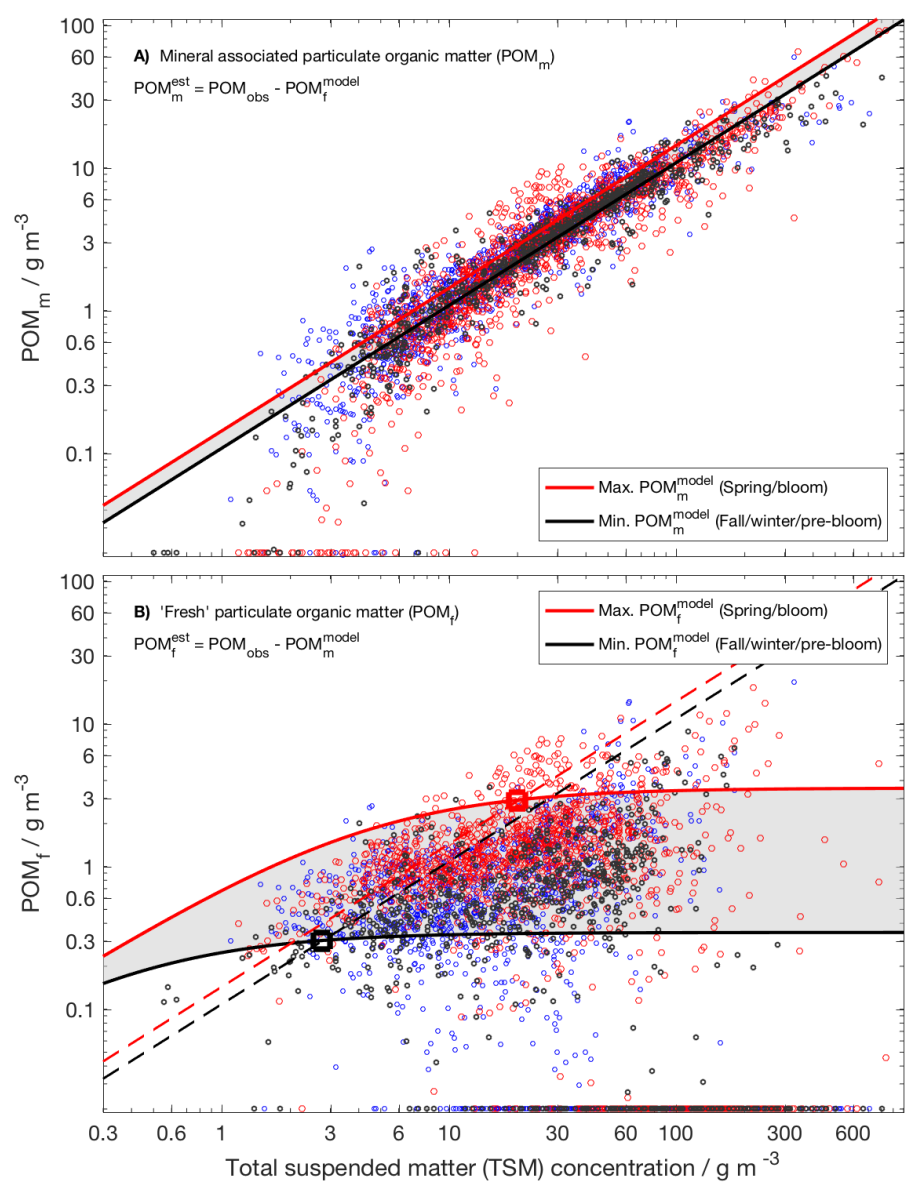

Figure 6: Relationship between concentrations of total suspended matter (TSM), fresh particulate organic matter $\left(\mathrm{POM}_{f}\right)$, and mineral associated particulate organic matter $\left(\mathrm{POM}_{m}\right)$, distinguished by the periods: Fall/winter/pre-bloom $=$ black, Spring/bloom $=$ red, and Summer/post-bloom = blue $)$. A) Estimates of $\mathrm{POM}_{m}\left(\mathrm{POM}_{m}^{\text {est }}\right)$ derived by subtracting $\mathrm{POM}_{f}^{\text {model }}$ from $\mathrm{POM}_{\text {obs }}$. Solid lines reveal $\mathrm{POM}_{m}$ as a function of TSM concentration, according to the POM-TSM model (maximum during Spring/bloom = red, minimum during the Fall/winter/pre-bloom period = black). B) Estimates of $\mathrm{POM}_{f}$ derived by subtracting $\mathrm{POM}_{m}^{\text {model }}$ from $\mathrm{POM}_{\text {obs }}$ (same colour code as in A). Solid lines reveal $\mathrm{POM}_{f}$ as a function of TSM, with a maximum during Spring/bloom (= red), and a minimum during the Fall/winter/pre-bloom period (= black). For comparison, lines of $\mathrm{POM}_{m}^{\text {model }}$ shown in A) are added as dashed lines. 
4.4. Quantitative and qualitative spatio-temporal variations of total suspended matter (TSM)

\subsubsection{Concentrations of TSM}

In the German Bight, TSM concentrations derived from remote sensing data vary by four orders of magnitude (approximately from 0.1 to $100 \mathrm{~g} \mathrm{~m}^{-3}$ ) (Fig.7). During all seasons we find highest TSM concentrations in the vicinity of the Wadden Sea tidal flats. Note that data were only calculated for areas where the water column exceeds five meters of depth, which includes the tidal channels of the Wadden Sea and the Ems, Weser, Jade, and Elbe estuaries (from West to East). The offshore, pelagic waters in the German Bight have depths between twenty and fourty meters and these areas reveal maxima in TSM concentrations up to $7 \mathrm{~g} \mathrm{~m}^{-3}$. At coastal sites, with depths of ten to fifteen meters, the TSM concentrations are mostly above $3 \mathrm{~g} \mathrm{~m}^{-3}$. Tidal mixing and wind induced resuspension events sustain a horizontal gradient in TSM concentration from tidal flats, the proximity of the Wadden Sea, to deeper pleagic waters. During summer, we find slighly lower TSM concentrations in the pelagic offshore areas, with clear water patches where TSM concentrations reach down to $0.3 \mathrm{mg} \mathrm{m}^{-3}$. Fig. 7 shows TSM concentrations for two consecutive years (2010 and 2011). Both years feature similar patterns. These patterns seem robust, because they also appear in the years 2008 and 2009 (see supplementary material).

4.4.2. Estimated concentrations of fresh particulate organic matter $\left(P M_{f}\right)$ If we adopt the seasonal varying values of $K_{\mathrm{POM}}$ and $m_{\mathrm{POM}}$ described before, we can specify the organic fractions of the remote sensing TSM data products (see supplementary material for the years 2008 through 2011). According to our model approach, we can discriminate between different 


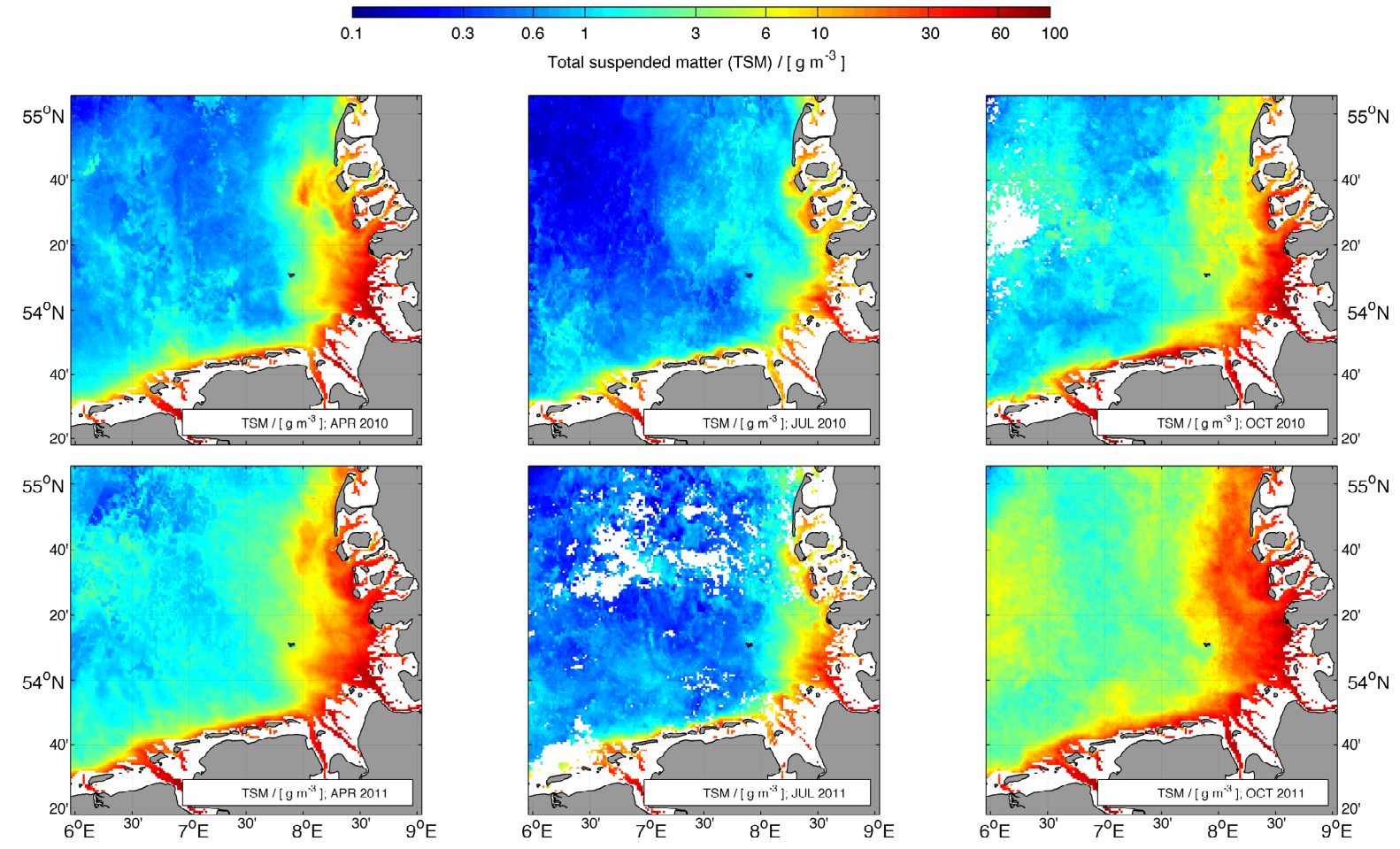

Figure 7: Monthly mean total suspended matter (TSM) concentrations derived from MERIS remote sensing data; comparison between two years (2010, upper panel and 2011 lower panel) for selected months (April, left; July, middle; October, right). The representative monthly scenes can be attributed to the Spring/bloom, Summer/postbloom, and Fall/winter/pre-bloom periods for the seasonal data subsets used for calibration of the POM-TSM model.

organic matter types and estimate the $\mathrm{POM}_{f}$ fraction of TSM, as shown before. If we consider the satellite-based TSM data we can derive monthly maps of $\mathrm{POM}_{f}$ concentrations (Fig.8). The temporal and spatial differences in $\mathrm{POM}_{f}$ reveal that the major seasonal formation of fresh POM occurs not only within the shallow coastal regions but extends to the deeper waters of the German Bight. Several patches of high $\mathrm{POM}_{f}$ concentrations 


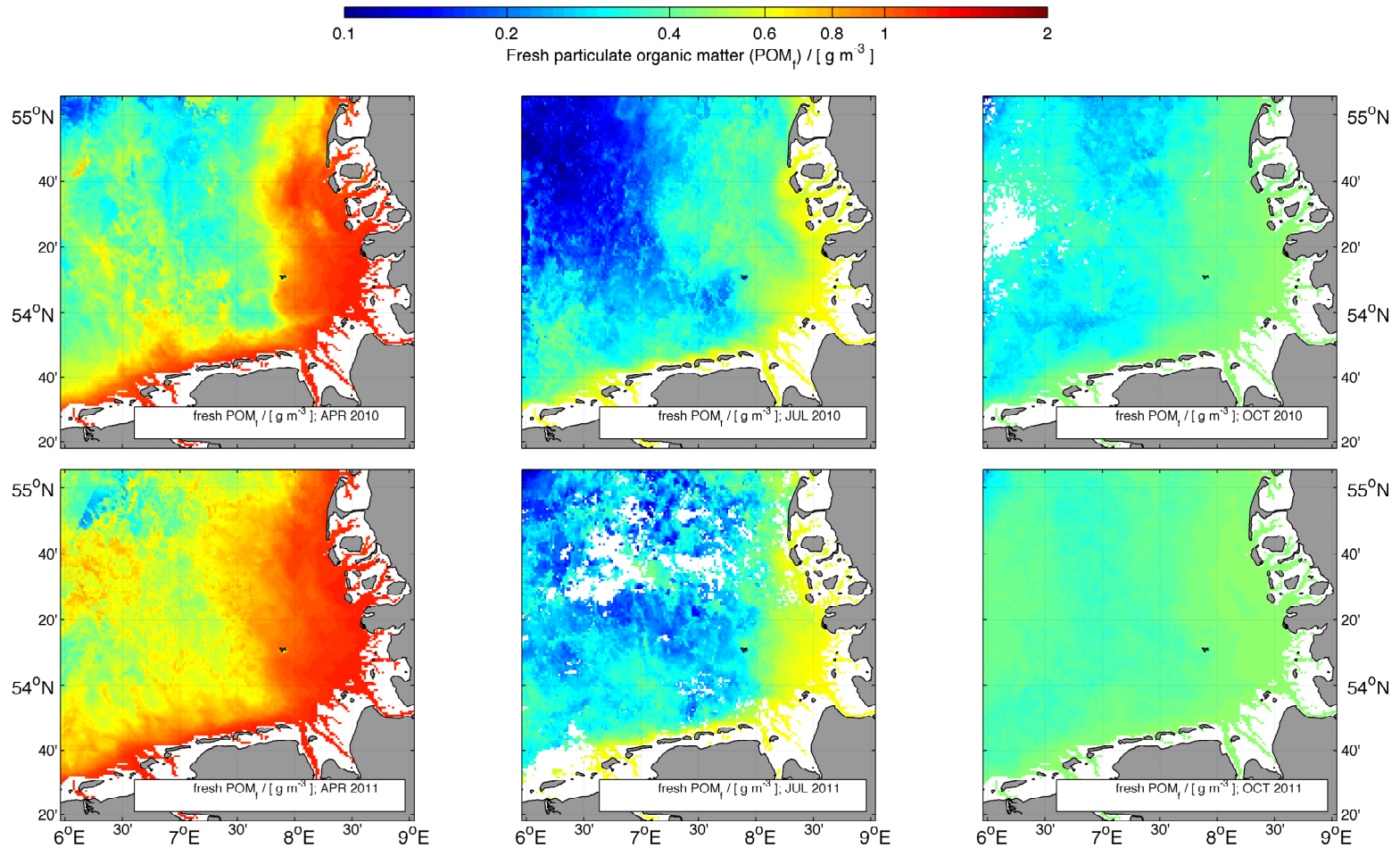

Figure 8: Monthly mean concentrations of fresh particulate organic matter $\left(\mathrm{POM}_{f}\right)$ of two consecutive years (2010 and 2011), estimated from total suspended matter (TSM) concentrations by applying the POM-TSM model. The representative monthly scenes can be attributed to the Spring/bloom, Summer/post-bloom, and Fall/winter/prebloom periods for the seasonal data subsets used for calibration of the POM-TSM model.

539 (with maxima above $1 \mathrm{~g} \mathrm{~m}^{-3}$ ) are allocated far offshore in April and in540 dividual filaments can be identified that disperse from coastal areas into ${ }_{541}$ the deeper pelagic waters, in particular along the East Frisian islands. In 542 general, we find horizontal gradients of $\mathrm{POM}_{f}$ concentrations to be well es543 tablished during spring, from the coastal zones to the pelagic areas. These 544 gradients are weakened but sustained throughout the summer period. The 
estimated $\mathrm{POM}_{f}$ concentrations decrease during summer to $0.2 \mathrm{~g} \mathrm{~m}^{-3}$ in the central German Bight. Although at lower concentrations than during the bloom period, $\mathrm{POM}_{f}$ is sustained within and nearby coastal regions $(\approx$ $\left.0.6 \mathrm{~g} \mathrm{~m}^{-3}\right)$. In these regions the $\mathrm{POM}_{f}$ decreases in late fall and during the winter period. In October, $\mathrm{POM}_{f}$ is distributed rather homogeneously, with concentrations between 0.3 and $0.5 \mathrm{~g} \mathrm{~m}^{-3}$. Possibly, the reduction of horizontal gradients in $\mathrm{POM}_{f}$ is introduced because of POM being slightly overestimated by our POM-TSM model at TSM concentrations below $1 \mathrm{~g}$ $\mathrm{m}^{-3}$ during this period.

\subsubsection{Spatial and temporal differences between concentrations of $\mathrm{POM}_{f}$ and} $\mathrm{POM}_{m}$

The absolute differences in concentration between $\mathrm{POM}_{m}$ and $\mathrm{POM}_{f}(\Delta \mathrm{POM}$ $=\mathrm{POM}_{m}-\mathrm{POM}_{f}$ ) reveal those regions where either $\mathrm{POM}_{m}$ or $\mathrm{POM}_{f}$ dominate. Fig.9 shows $\triangle$ POM for the years 2010 and 2011 for the same months as depicted in Figs.7 and 8. The transition from $\mathrm{POM}_{m}>\mathrm{POM}_{f}$ to $\mathrm{POM}_{f}$ $>\mathrm{POM}_{m}$ is associated with some general uncertainties in total POM $(\approx$ $1 \mathrm{~g} \mathrm{~m}^{-3}$ for TSM $>10 \mathrm{~g} \mathrm{~m}^{-3}$ and $\approx 100 \mathrm{mg} \mathrm{m}^{-3}$ for TSM $<10 \mathrm{~g} \mathrm{~m}^{-3}$, Fig.5). In Fig.9, this transition is individually highlighted (colored) for the ranges of $\triangle \mathrm{POM}$ between -100 and $100 \mathrm{mg} \mathrm{m}^{-3}$. The analysed fields of our Spring/bloom period reveal four transitional zones that stretch parallel along the coastline of the German Bight. $\mathrm{POM}_{m}$ dominates within a first zone close to the coast, enclosing a region of repeated resuspension events and of transport of sediment associated POM (with depths $\mathrm{z}<12 \mathrm{~m}$ ). The second zone is rather narrow. It marks the transition from shallower coastal to deeper waters where the amount of originally primary produced $\mathrm{POM}_{f}$ is similar to $\mathrm{POM}_{m}(\mathrm{z} \approx 12-14 \mathrm{~m})$. A third zone indicates predominance of 


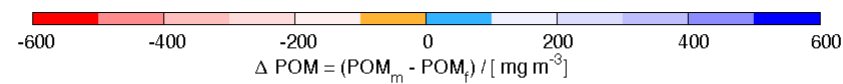
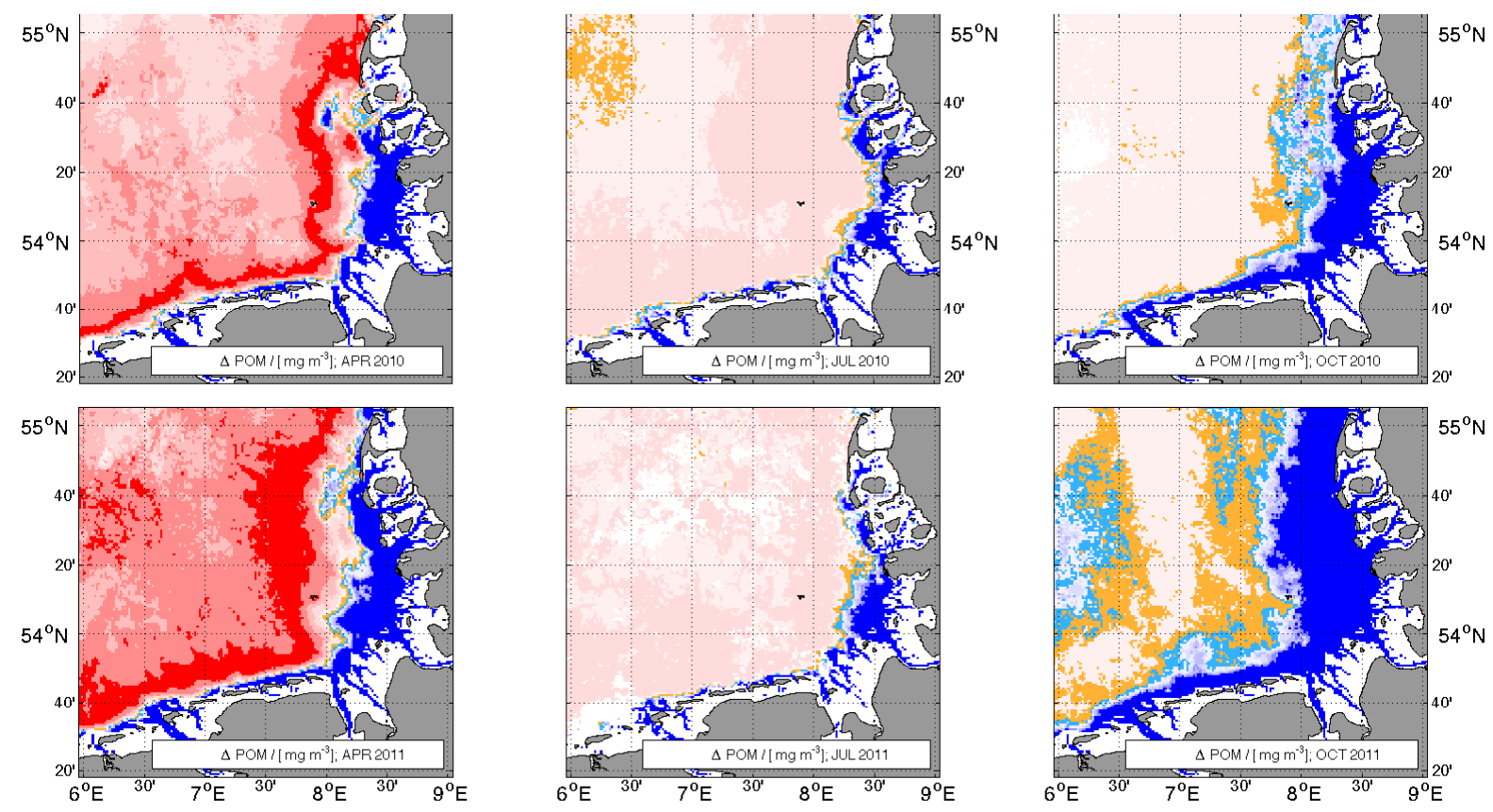

Figure 9: Difference between fresh particulate organic matter $\left(\mathrm{POM}_{f}\right)$ and the fraction that is proportional to particulate inorganic matter concentration (mineral associated $\mathrm{POM}_{m}$ ) for the years 2010 and 2011. The blue color code indicate $\mathrm{POM}_{m}$ concentrations that exceed $\mathrm{POM}_{f}$. The red color code show where $\mathrm{POM}_{f}$ concentrations exceed $\mathrm{POM}_{m}$. The transition from $\mathrm{POM}_{m}>\mathrm{POM}_{f}$ to $\mathrm{POM}_{f}>\mathrm{POM}_{m}$ are explicitly marked orange and cyan $\left( \pm 100 \mathrm{mg} \mathrm{m}^{-3}\right)$. These orange/cyan colored areas thus exhibit those coastal ocean regions where $\mathrm{POM}_{f}$ and $\mathrm{POM}_{m}$ approach similar concentrations.

$571 \mathrm{POM}_{f}$ already, but there is a distinctive fourth zone that consitutes a maxi572 mum in $\mathrm{POM}_{f}$ production (with $\Delta \mathrm{POM}<-500 \mathrm{mg} \mathrm{m}^{-3}$ ). Further offshore 573 (with $\mathrm{z}>25 \mathrm{~m}$ ) the overall $\mathrm{POM}_{f}$ concentrations decrease again, which ex574 plains the slight increase of $\Delta \mathrm{POM}$ to values between -400 and $-200 \mathrm{mg} \mathrm{m}^{-3}$ 575 in the deeper pelagic waters. The four zones reduce to a pattern of three 
zones during the Summer/post-bloom period. A remarkable feature is the coastward movement of the second zone: some coastal areas where $\mathrm{POM}_{m}$ prevailed during the Spring/bloom period have turned into regions where either $\mathrm{POM}_{f}$ dominates or where concentrations of $\mathrm{POM}_{m}$ and $\mathrm{POM}_{f}$ are similar. During the Fall/winter/pre-bloom conditions the horizontal $\triangle \mathrm{POM}$ pattern again changes, with some clear dispersion of $\mathrm{POM}_{m}$ away from the shallow areas $(\mathrm{z}<12 \mathrm{~m})$ into regions of greater water depths (with $\mathrm{z}>$ $20 \mathrm{~m}$ ). The Fall/winter/pre-bloom $\mathrm{POM}_{f}$ concentrations in the offhore regions are low and are associated with some uncertainties, as suggested by the differences in $\triangle \mathrm{POM}$ patterns between the years 2010 and 2011.

\subsection{Monthly quantitative and qualitative variations of TSM at a local site}

By applying our simple POM-TSM model to remote sensing data of the southern North Sea and the German Bight, coherent and distinctive patterns in the distribution of TSM, $\mathrm{POM}_{m}$, and $\mathrm{POM}_{f}$ emerge. This is not selfevident as natural variations of TSM concentration and observational noise may mask seasonal and local TSM features. In the following we briefly evaluate the model's ability to resolve seasonal changes in local TSM. We explore quantitative and qualitative changes of TSM in the vicinity of Helgoland. This area is of particular interest because of its proximity to the coastal shallow Wadden Sea and the Elbe estuary, introducing substantial variability in TSM quality and concentrations. The region around Helgoland is between 20 and $28 \mathrm{~m}$ deep on the northern side and up to $50 \mathrm{~m}$ to the south and west. We selected in situ measurements (water samples from ship cruises) and remote sensing data from an area around Helgoland that extends from $54.1^{\circ} \mathrm{N}$ to $54.25^{\circ} \mathrm{N}$ and from $7.75^{\circ} \mathrm{E}$ to $8.10^{\circ} \mathrm{E}$. The in situ measurements cover a four year period, starting in 2010 and mean monthly values were calculated 
whenever possible and compared to the mean monthly remote sensing data, covering a period from the year 2009 to 2012. Thus, mean monthly satellite and field data include both spatial variations within the above defined domain as well as interannual variability. All monthly TSM and POM concentrations (Figs.10A and 10B) are shown together with respective organic matter fractions (Figs.10C). The corresponding concentrations of $\mathrm{POM}_{m}$ and $\mathrm{POM}_{f}$ were derived with the POM-TSM model (Figs.10D and 10E), based on our seasonal parameter estimates (Table 2). We also determined differences between $\mathrm{POM}_{m}$ and $\mathrm{POM}_{f}$ (Fig.10F).

Variability in TSM concentration is greatest during late fall and winter, with variations between 1 and $35 \mathrm{~g} \mathrm{~m}^{-3}$ occuring already in October. TSM is distributed rather homogeneously around Helgoland during June and July, with concentrations that remain well below $5 \mathrm{~g} \mathrm{~m}^{-3}$. Seasonality and differences in are in line with the in situ data. During May and July, however, some TSM in situ measurements exhibit concentrations that are higher than those derived from remote sensing. Based on the POM TSM model, the organic matter fraction has its maximum during June. For the same month the POM concentrations are low $\left(<1.5 \mathrm{~g} \mathrm{~m}^{-3}\right)$, which correspond to in situ measurements. The field observations yield POM concentrations that are higher than those derived from the satellite data during July. This is associated with in situ TSM concentrations being higher as well. Seasonal variations in $\mathrm{POM}_{m}$ concentration in the waters around Helgoland mainly reflect changes in TSM concentration, with a minimum in June. The temporal pattern is clearly different from $\mathrm{POM}_{f}$ that reaches its maximum during the spring bloom in April and then gradually decreases throughout the summer period. Apparently, the POM-TSM model resolves the temporal offset between concentrations of $\mathrm{POM}_{m}$ and $\mathrm{POM}_{f}$ well. The model further pre- 

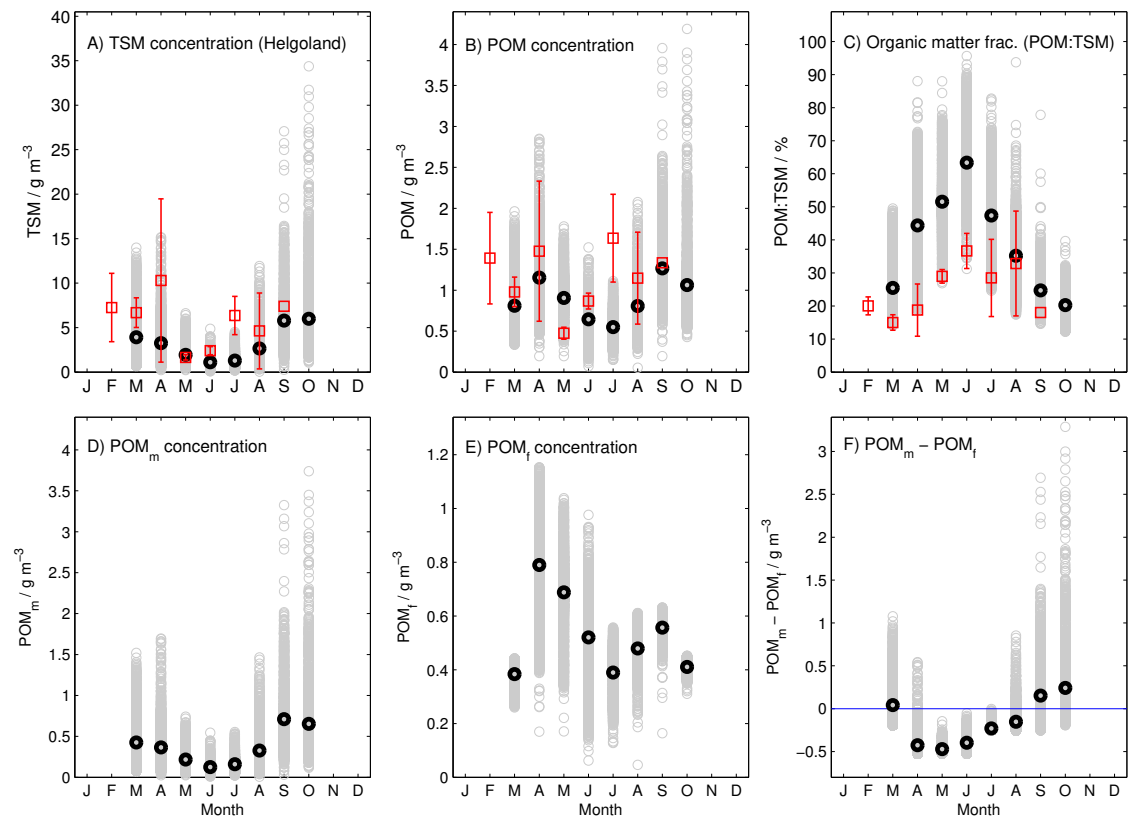

Figure 10: Seasonal quantitative and qualitative changes of total suspended matter (TSM) around Helgoland island (from $54.1^{\circ} \mathrm{N}$ to $54.25^{\circ} \mathrm{N}$ and from $7.75^{\circ} \mathrm{E}$ to $8.10^{\circ} \mathrm{E}$ ). The gray circles show data that were calculated from MERIS remote sensing TSM concentrations from the years 2009 - 2012 (A), applying the POM-TSM model to derive POM concentrations (B). The black dots indicate mean values of respective data derived from remote sensing. The red squares show mean values of in situ TSM, and POM concentrations, and loss-on-ignition (LoI) measurements. Seasonal changes of the percentage of organic matter in TSM (POM:TSM $\times 100 \%)$ are shown on C). Subplots D), E), and F) exhibit seasonal variations of mineral associated $\mathrm{POM}\left(\mathrm{POM}_{m}\right)$, fresh $\mathrm{POM}\left(\mathrm{POM}_{f}\right)$ and the difference $\Delta \mathrm{POM}=\mathrm{POM}_{m}-\mathrm{POM}_{f}$, as derived from remote sensing data.

dicts that $\mathrm{POM}_{f}$ prevails during spring and summer (April - August). In turn, $\mathrm{POM}_{m}$, presumably originating from the nearby coastal areas and the Elbe estuary, dominates the POM pool from October through March. 


\section{Discussion}

\subsection{POM-TSM model and the mixing model approach}

Many studies documented an increase of the TSM's organic content with decreasing TSM concentration (e.g. Eisma and Kalf, 1987; Balls, 1990; Jago et al., 1993; Sempéré et al., 2000), which is a robust feature of coastal and estuary regions. Morris et al. (1987) describe the observed elemental changes in TSM as a mixture of two distinct types of bulk particles that differ in origin and composition. This approach was adopted by Bale and Morris (1998) for estimating particulate organic carbon (POC) from TSM concentrations. According to their assumption, the organic carbon fraction $\left(f^{\mathrm{C}}\right)$ of TSM is a mixture between a POC fraction (e.g. algae and zooplankton) that resides permanently within the water column $\left(f_{0}^{\mathrm{C}}\right)$ and a residual fraction $\left(f_{\mathrm{r}}^{\mathrm{C}}\right)$ of resuspended sediment (bed) material. Thus, total POC concentrations are derived by multiplying TSM loads of different origin with their corresponding carbon fractions, $f_{0}^{\mathrm{C}}$ and $f_{\mathrm{r}}^{\mathrm{C}}$ respectively: $\mathrm{POC}=\mathrm{TSM} \cdot f^{\mathrm{C}}=\mathrm{TSM}_{0}$. $f_{0}^{\mathrm{C}}+\left(\mathrm{TSM}-\mathrm{TSM}_{0}\right) \cdot f_{\mathrm{r}}^{\mathrm{C}}$, with $\mathrm{TSM}_{0}$ being the permanently suspended load and the residual load $\left(\mathrm{TSM}-\mathrm{TSM}_{0}\right)$ of resuspended sediment particles. Solving for the total carbon fraction gives us: $f^{\mathrm{C}}=\mathrm{TSM}_{0} / \mathrm{TSM}$. $\left(f_{0}^{\mathrm{C}}-f_{\mathrm{r}}^{\mathrm{C}}\right)+f_{\mathrm{r}}^{\mathrm{C}}$. In this "mixing" model, the sediment associated carbon fraction $f_{\mathrm{r}}^{\mathrm{C}}$ is similar to our $m_{\mathrm{POM}} /\left(m_{\mathrm{POM}}+1\right)$. Thus, for high TSM concentrations $\left(>30 \mathrm{~g} \mathrm{~m}^{-3}\right.$ ) the difference between the mixing model and our parameterization is negligible.

The major difference between the mixing model of Morris et al. (1987) and our approach is in the asymptotic behaviour at low TSM concentrations. The formulation of a mixture of two sub-components introduces an inverse (hyperbolic) relationship between TSM concentrations and its constituent 
loads. Actually, Morris et al. (1987) explained that the constituent loads do not show a clear linear dependence of the inverse TSM as predicted by their model. Rather, their data exhibit an asymptotic behaviour towards some saturation level for low TSM concentrations; a feature that is naturally described by our POM-TSM model. Interestingly, the observations displayed in Morris et al. (1987), Jago et al. (1993), and Bale and Morris (1998) show discernable, systematic deviations from their two sub-component mixing model regression. The residuals of their linear regressions (as a function of 1/TSM concentration) are not randomly distributed but become negative towards low and positive towards high TSM concentrations.

The sensitivity of the mixing model's results to small variations in TSM at low concentrations $\left(<1 \mathrm{~g} \mathrm{~m}^{-3}\right)$ is excessive, and small uncertainties in the slope estimates $\mathrm{TSM}_{0}$ and $f_{0}^{\mathrm{C}}$ eventually translate into large uncertainties in corresponding POC estimates. Given these uncertainties, the mixing model's POC concentrations may even exceed those of TSM and therefore some lower TSM cut-off concentration has to be provided for which POC concentrations remain meaningful. We did not find similar limitations with our POM-TSM model. However, a potential advancement could be combining aspects of the mixing model idea of Morris et al. (1987) with our model that does not require a permanent $\mathrm{TSM}_{0}$ load.

\subsection{Potential improvements and limitations of the POM-TSM model}

A potential improvements could be to refine the POM-TSM model by introducing an additional parameter $\left(f_{0}\right)$ that further separates between the mixing of $\mathrm{POM}_{f}$ and $\mathrm{POM}_{m}$ and their contributions to the LoI signal (see Appendix Appendix C, Eq.(C.2). This way we can resume the original idea of Bale and Morris (1998) discussed before. However, Eq.(C.2) reveals that 
a unique identification of $f_{0}$, independent from $K_{\mathrm{POM}}$ and $m_{\mathrm{POM}}$ estimates, will be difficult to achieve. It is because of these collinearities why an introduction of $f_{0}$ may not be automatically accompanied with advanced POM estimates. The underlying mixing problem is underdetermined (e.g. Fry, 2013), unless independent data or information other than LoI, like isotopic ratios (e.g. Liénart et al., 2017), can be considered as additional constraints for estimating $f_{0}$. A simpler and more promising approach is to improve the application of the POM-TSM model by further resolving spatio-temporal variations of the values assigned to $m_{\mathrm{POM}}$ and $K_{\mathrm{POM}}$.

\subsubsection{Spatio-temporal variations of the parameters $m_{P O M}$ and $K_{P O M}$}

Optimal estimates of the proportionality factor $m_{\mathrm{POM}}$, which determines the fraction of $\mathrm{POM}_{m}$, reveal only a weak seasonal dependence, as those estimates remain similar between seasons (Table 2). The slightly higher estimate for the Summer/post-bloom period may be associated with enhanced deposition of TSM during summer time, which increases the organic matter composition of the benthic boundary layer (Fettweis et al., 2014; Fettweis and Baeye, 2015). Substantial variability seen in the data at high TSM concentrations is likely attributable to different sediment types. Large areas of the German Bight are covered with sandy sediments with sand fractions of at least $20 \%$ of total sediment (Figge, 1981). In addition, these sandy regions differ with respect to the prevailing grain size and porosity, which may cause substantial variations in $\mathrm{POM}_{m}$ concentrations with the resupension of sandy sediments. Tidal flats typically contain mud sediments that incorporate a larger fraction of organic matter compared to sandy sediments (Flemming and Delafontaine, 2000). This variation is quite complex in the Wadden Sea and the shallow reaches of the estuarine river mouths. 
Following the attenuation of wave height and tidal current amplitudes with decreasing water depth, tidal flat sediments are sandy at the more exposed sites and muddy along the fringes. This general gradient is further superimposed by patches of fine-grained sediment due to benthic biogenic structures (Flemming and Nyandwi, 1994). Because of the high permeabliity of sandy sediments and the high amount of TSM, Wadden Sea sandy sediments may accumulate substantial amounts of fines (clays, organic mattter) in the interstitial (e.g. Rusch and Huettel, 2000) that may be released during resuspension of these sediments. Thus, resuspension events at different locations leave different imprints in the $\mathrm{POM}_{m}: \mathrm{PIM}$ ratio (represented by the parameter $\left.m_{\mathrm{POM}}\right)$.

For a quantitative support of these considerations we may refer to erosion experiments with field samples, carried out on several surveys on intertidal flats in the North Frisian Wadden Sea between 1995 and 1997. The sampling locations and methodologies for erosion and sediment laboratory analyses are described in Riethmüller et al. (2000). Water samples with eroded material were taken during the erosion experiments and TSM concentrations and LoI determined from filtering and combustion to compute rates of eroded material as a function of applied bed shear stress. In all cases, the same laboratory procedures as described above were applied. In addition, the mud content (\% grain size $<63 \mu \mathrm{m}$ ) and the LoI of the first upper millimeter (i.e. the layer usually subject to erosion or resuspension) of the sampled sediment was determined. The mud content of the surface sediments was between $2 \%$ and $80 \%$, sediment surface LoI varied between $1 \%$ and $12 \%$ and eroded matter LoI between $1 \%$ and $25 \%$. The LoI data of both the sediment surface and eroded matter are significantly positively correlated with the mud content $\left(\mathrm{P}<10^{-8}\right)$ exhibiting the dependence of LoI on the 
sediment surface types. Moreover, the average LoI of the eroded matter was about $9 \%$, just in the range of the LoI of the TSM samples $>200 \mathrm{~g} \mathrm{~m}^{-3}$. This nicely emphasizes the sediment surfaces as the origin of the suspended matter in the shallow coastal waters, here specifically in the Wadden Sea.

In contrast to $\mathrm{POM}_{m}$, temporal variations in $\mathrm{POM}_{f}$ seem predominant. Our seasonally varying estimates of $K_{\mathrm{POM}}$ are well constrained by data of TSM concentrations below $30 \mathrm{~g} \mathrm{~m}^{-3}$. At the same time, the variability in LoI measurements has its maximum during the Spring/bloom period and it is related to TSM concentrations between 10 and $40 \mathrm{~g} \mathrm{~m}^{-3}$, which cannot be fully explained with the POM-TSM model. Fettweis et al. (2007) analysed spatio-temporal variability of TSM concentrations within the Belgian-Dutch coastal zone. Using remote sensing (SeaWiFS) data of TSM they found the relative variability in TSM (standard deviations of TSM concentration during a tidal cycle divided by respective seasonal averages) to have distinct maxima between $20 \mathrm{~g} \mathrm{~m}^{-3}$ during spring and summer and $40 \mathrm{~g} \mathrm{~m}^{-3}$ during fall. Variability in our LoI data may thus be associated with variations in tidal transport, with organic fractions of TSM that originate from shallow coastal regions being generally higher than those of the deeper pelagic layers. Thus, spatial differences in the distribution of $\mathrm{POM}_{f}$ along the coast may translate into substantial variations in LoI measurements, depending on the direction and intensity of tidal transport. In the southern North Sea these pronounced LoI variations are accompanied with TSM concentrations between 10 and $40 \mathrm{~g} \mathrm{~m}^{-3}$.

Temporal changes in $K_{\mathrm{POM}}$ values mainly reflect the cumulative amount of primary produced POM and its subsequent decay. A possible advancement of the POM-TSM model would be to prescribe some proportionality between $K_{\mathrm{POM}}$ and changes in nutrient concentrations during a seasonal 
cycle. The maximum achievable value of $K_{\mathrm{POM}}$ likely depends on the production potential (or carrrying capacity) of the planktonic ecosystem, which is proportional to the nutrient concentrations observed before the onset of the spring bloom, e.g. during the winter period. A seasonal increase of $K_{\mathrm{POM}}$ may then be simply described as being negatively correlated with nutrient availability (i.e. deviations from maximum winter concentrations). As nutrients concentrations approach their lower limit, the $K_{\mathrm{POM}}$ converges towards its maximum value. Conversely, the remineralization of POM leads to an increase in nutrient concentrations and thus introduces a gradual decline in $K_{\mathrm{POM}}$ values to some lower limit. This way temporal variability in LoI could possibly become better resolved with the TSM-POM model. Likewise, regional differences, due to variations in nutrient supply (e.g. within or nearby estuaries or small river mouths) could be accounted for as well. An assessment of the potential and feasibility of such an approach is lacking, but some further analyses in this respect seem meaningful.

\subsubsection{Variablity and upper limits of LoI}

By merging observational LoI data that differ in how samples were collected and measured, we may expect to further introduce uncertainties, possibly adding some bias and variations. These uncertainties are not resolved by our methodological error $\left(\sigma_{\text {method}}\right)$ and may be insufficiently covered by the observational sampling error $\left(\sigma_{\mathrm{SV}}\right)$. Considerable differences between data sets might be related to differently applied protocols. For example, in Section 4.1 we introduced data from the study of Hommersom et al. (2009). The main purpose was to evaluate possible differences in optimal parameter estimates, when using data from another independent source. The optimization resulted in significant differences in the parameter estimates 
compared to those estimates obtained with our data. This may partially be attributable to the sampling area. Their Wadden Sea data are associated with TSM concentrations always greater than $2 \mathrm{~g} \mathrm{~m}^{-3}$, with only five measurements of LoI below $10 \%$ (Fig.4). But we also learned that there are some differences in the LoI determination of Hommersom et al. (2009) compared to our procedure, with a much longer combustion time of 5 hours at comparable temperatures. As explained in Wang et al. (2011), this already results in a few percent higher LoI compared to our data. These findings stress the value of inter-calibration exercises and that some care should be taken by combining LoI data.

For TSM concentrations that approach zero we assume that LoI converges towards $1(100 \%)$ or POM towards TSM. This holds true if only organic substances remain on the filter that can be fully combusted. Furthermore, in the derivation of our TSM-POM model we only consider a single pool of PIM, thereby neglecting a possible distinction between fresh biogenic PIM $\left(\mathrm{PIM}_{b}\right)$ and other mineral PIM that is associated with lithogenic material $\left(\mathrm{PIM}_{l}\right)$. But in case of the main primary producers in the coastal North Sea, the neglect of such distinction may introduce some uncertainty to the upper limit in LoI that can actually be achieved at low TSM concentrations (e.g. TSM $<1 \mathrm{~g} \mathrm{~m}^{-3}$ ). In particular, diatoms can be abundant during the spring blooms (e.g. Rick et al., 2006) and diatom frustules (and some phosphate) will remain after combustion, lowering the LoI. Ríos et al. (1998) reported an elemental phytoplankton composition (C:H:O:N:P:Si) of 106:178:60:15:1.2:7. Assuming that only $\mathrm{PO}_{4}^{3-}$ and $\mathrm{SiO}_{2}$ remain after combustion, LoI is about $0.93(93 \%)$ for non-diatoms and about $0.83(83 \%)$ for diatoms. In the presence of diatoms the LOI measurements strongly depend on the amount of silicification. Ríos et al. (1998) found an N:Si 
ratio of 2, while Brzezinski (1985) reported a value of 1 , which is similar to the DIN:Si uptake ratio observed in the northern Wadden Sea during spring (van Beusekom et al., 2009). If we adopt the N:Si ratio of 1 reported by Brzezinski (1985) we obtain a LoI of diatoms of about $0.78(78 \%)$ for a diatom dominated spring bloom. In case of low TSM concentrations it may well be the case that the TSM weight is largely dominated by diatoms and LoI values would approach values of about 0.8 , depending on the remaining fraction of non-silificifying phytoplankton. In our analyses, the highest LoI observed remain below this limit and the TSM-POM model yield estimates close to $0.8(\mathrm{LoI} \approx 80 \%)$ at TSM concentrations lower than $0.6 \mathrm{~g} \mathrm{~m}^{-3}$ for the spring period and lower than $0.3 \mathrm{~g} \mathrm{~m}^{-3}$ for the other seasons (as can be seen in Fig.3).

Another possible source of uncertainty in LoI is caused by dissolved organic matter adsorption onto filters, which can affect combustion measurements. The adsorption of dissolved organic carbon (DOC) has been described and discussed by Middelburg and Herman (2007). The amount that can be adsorped depends on the concentrations of surface-active DOC, likely introducing additional variability to the organic fraction of TSM. The effect of DOC adsorption can become particulary relevant for situations where $\mathrm{C}: \mathrm{N}: \mathrm{P}$ ratios of POM are high, e.g. during periods when algal growth is limited by nutrients availability while photosynthesis (carbon fixation) is sustained. Since DOC does not contain biogenic Si, the effect of DOC adsorption can counteract the lowering of LoI induced by the presence of biogenic silcate. However, a lack of data for the coastal German Bight precludes estimating the potential effect of DOC adsorption on those LoI measurements that are available for our study. 


\subsection{Portability of the POM-TSM model}

\subsubsection{Regional differences}

The portability of our POM-TSM model can be assessed by testing whether it may also be used to explain LoI and TSM data at other regions. Fig.11A shows additional fits of the POM-TSM model to our sample data collected at different bay and estuary areas: a) Oosterschelde (Netherlands), b) Ria de Vigo (Spain), and c) Limfjorden (Denmark). The model fits to data of Limfjorden and Ria de Vigo are similar and compare well with the model results for the German Bight data. The organic fractions of TSM of the Oosterschelde are only slightly less than those of Limfjorden and Ria de Vigo, but at higher TSM concentrations between 3 and $30 \mathrm{~g} \mathrm{~m}^{-3}$. These comparably high LoI are attributable to an intense Phaeocystis bloom that occurred during the Oosterscheldt survey (Herman, 2006, p. 54). The POMTSM model is thus well suited to resolve similarities and differences between regions. Zhang et al. (2014) compared POM and TSM concentrations between Monterey Bay and Mobile Bay (west and south of the United States). They found TSM concentrations to be generally lower within the Monterey Bay area than in the Mobile Bay. Accordingly, the Monterey Bay's mean organic fraction of TSM (POM:TSM $=0.79$, with mean $\mathrm{TSM}=0.86 \mathrm{~g}$ $\mathrm{m}^{-3}$ ) was higher than in the Mobile Bay region (POM:TSM $=0.25$, with mean TSM $=2.98 \mathrm{~g} \mathrm{~m}^{-3}$ ). The differences between these bay areas in Zhang et al. (2014) are in accordance with our calibrated POM-TSM model results, although fitted to measurements in the German Bight.

\subsubsection{Resolving particulate organic carbon}

Concentrations of TSM and of particulate organic carbon (POC) along the Belgian coast were analysed by Fettweis and Lee (2017). In their study the 
POC:TSM ratios of the near coast turbidity maximum zone were compared with ratios at locations further offshore. They show that the organic carbon fraction typically ranges between 2 and $5 \%$ for TSM concentrations greater than $100 \mathrm{~g} \mathrm{~m}^{-3}$. Similar to our findings, largest variations in the POC:TSM ratio emerge at TSM concentrations below $30 \mathrm{~g} \mathrm{~m}^{-3}$. For comparison we derived some first estimate of the POC fraction of TSM by assimilating collected data of Ittekkot and Laane (1991) into a refined version of the POM-TSM model. The refinement requires an additional parameter, whose value expresses the carbon fraction of the POM fraction of TSM. Our fit suggest $\mathrm{POC}$ fraction of $\approx 9 \%$ (POC:TSM=0.09) for TSM concentrations below $1 \mathrm{~g} \mathrm{~m}^{-3}$ and $\approx 1-2 \%$ (POC:TSM=0.01-0.02) for TSM $>100 \mathrm{~g}$ $\mathrm{m}^{-3}$ (Fig.11B). These estimates are lower but still comparable with those values found by Fettweis and Lee (2017). Even lower POC fractions of $<$ $1 \%$ (POC:TSM < 0.01) ratio were found in measurements of Wang et al. (2017) in the Taiwan Strait. In their study only vertical flux (settling) data of TSM were used and we can only speculate that these low POC fractions correspond with TSM concentrations greater than $100 \mathrm{~g} \mathrm{~m}^{-3}$. Overall, the assimilation of data into the POM-TSM model seems useful and it is not restricted to the German Bight.

\subsubsection{Relationship between $P O M_{f}$ and chlorophyll a}

For the derived $\mathrm{POM}_{f}$ it may seem plausible expecting these estimates to correlate well with observed chlorophyll a concentrations. Unfortunately, a comparison between concentrations of chlorophyll $a$ and $\mathrm{POM}_{f}$ is not straightforward. The relationship between both can be highly non-linear, with extensive variations in the chlorophyll $a$-to- $\mathrm{POM}_{f}\left(\mathrm{Chl}: \mathrm{POM}_{f}\right)$ ratio. Three major aspects need to be considered: i) the $\mathrm{POM}_{f}$ includes 


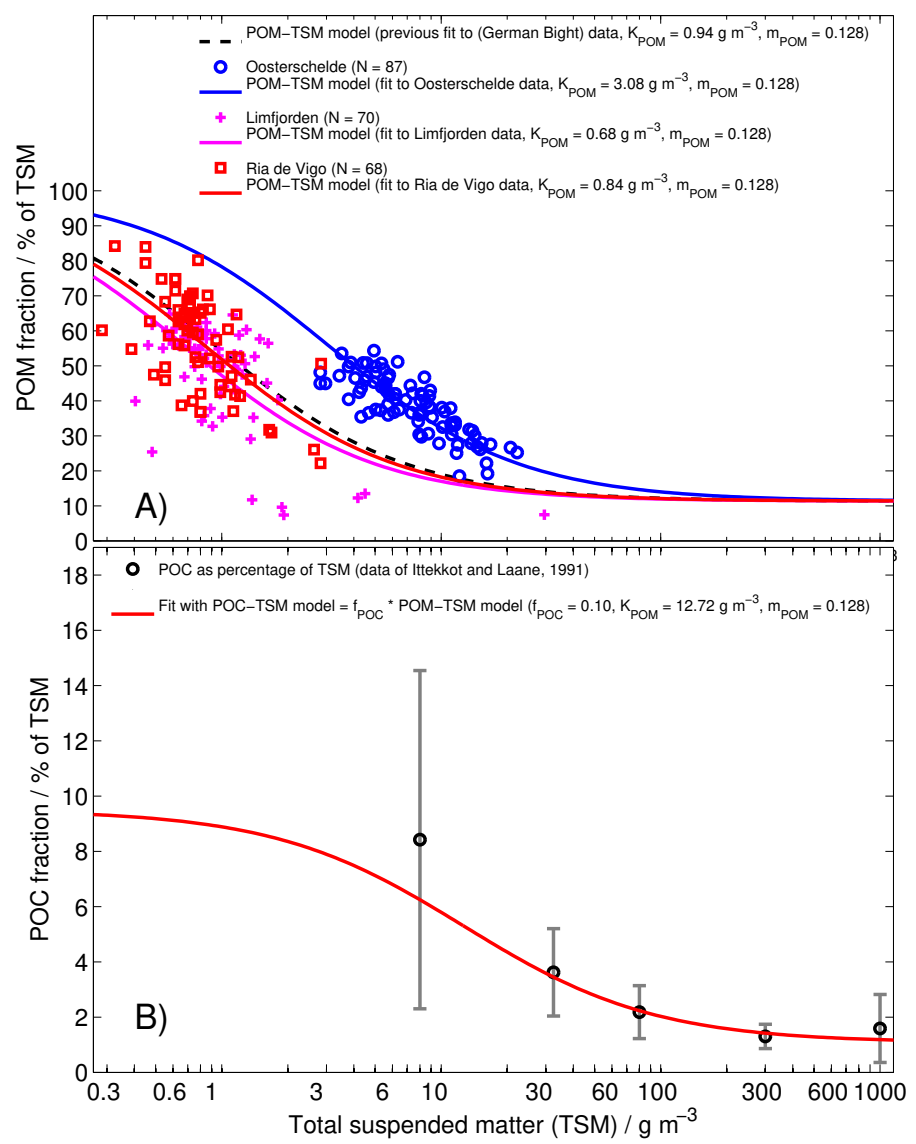

Figure 11: A) Application of the POM-TSM model to explain indpendent LoI data within regions other than the German Bight. For these fits the parameter $m_{\mathrm{POM}}$ was fixed to 0.128 (based on our estimates for the no season data subset, as given in Table 2). B) A fit to the particulate organic carbon (POC) percentage of TSM, when applying the POM-TSM model but multiplying its loss-on-ignition (LoI) results with a factor $\left(f_{\mathrm{POC}}\right)$ that represents the carbon fraction of the LoI signal.

heterotrophic organisms that have assimilated (consumed) parts of the primary produced organic matter, ii) the stoichiometric elemental composition of the phytoplankton can change significantly (e.g. Geider and La Roche, 2002), with carbon-to-nitrogen (C:N) ratios that easily differ by a factor of 
three, and iii) the chlorophyll $a$-to-carbon ratio can vary by two orders of magnitude, depending on the nutrient and light conditions (e.g. Jakobsen and Markager, 2016). The complex interdependency between chlorophyll $a$ and $\mathrm{POM}_{f}$ remains unresolved with our POM-TSM model.

If restricted to the bloom period, a comparison between chlorophyll $a$ and $\mathrm{POM}_{f}$ can be instructive, provided that predominant variations of the Chl:POM $f$ ratio can also be accounted for. We may apply a simple proxy for a variable Chl:POM $\mathrm{PO}_{f}$ ratio $\left(\Theta_{v}\right)=4 \mathrm{mg} \mathrm{g} \mathrm{g}^{-1}+9 \mathrm{~m}^{3} \mathrm{~g}^{-1} \times \mathrm{POM}_{f}$, which mimics the effect due to variable light conditions, from low light (high Chl:POM $f$ ratio) to high light (low Chl:POM $f$ ratio). For the bloom period we can assume that the $\mathrm{POM}_{f}$ is dominated by phytoplankton whose $\mathrm{C}: \mathrm{N}$ ratio is not subject to strong variations. Fig.12A compares chlorophyll $a$ concentrations obtained from remote sensing measurements of the Spring/bloom period (April - June, years 2008 - 2012) with estimates derived from $\mathrm{POM}_{f}\left(\mathrm{Chl} a_{\text {est }}\right)$, while imposing a constant Chl:POM $f$ ratio = $6\left[\mathrm{mg} \mathrm{g}^{-1}\right]$. For TSM $>6 \mathrm{~g} \mathrm{~m}^{-3}$ the $\mathrm{Chl} a_{\text {est }}$ tend to underestimate the satellite based Chl $a$ concentrations. With the introduction of the variable $\mathrm{Chl}: \mathrm{POM}_{f}$ ratio it is possible to compensate for this deficiency (Fig.12B). In Fig.12C we see the corresponding relationship between concentrations of TSM and Chl $a$, with the lines indicating the Chl $a_{\text {est }}$ based on the POMTSM model. The results of this comparison are promising and they further substantiates the potential and reliability of the $\mathrm{POM}_{f}$ estimates obtained with the POM-TSM model. Thus, reasonable Chl $a_{\text {est }}$ can be derived from TSM concentrations, as long as phytoplankton biomass prevails and by accounting for photo-acclimation effects. 

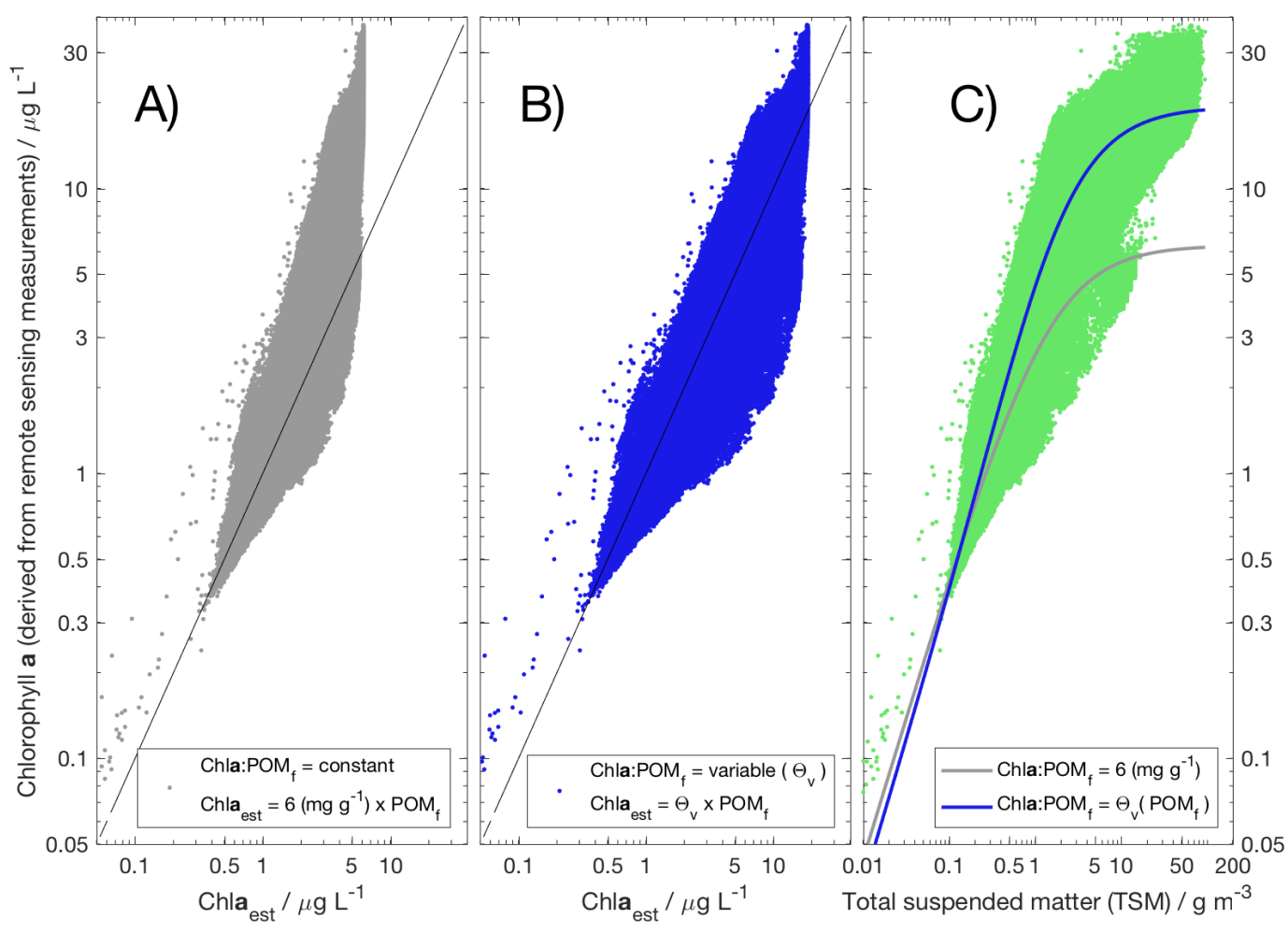

Figure 12: Evaluation of the relationship between chlorophyll $a$ concentrations obtained from remote sensing measurements and those derived from the POM-TSM model (Chl $\left.a_{\text {est }}\right)$. The comparisons refer to data of the Spring/bloom period (April June, years 2008 - 2012, with parameter estimates $K_{\mathrm{POM}}=1.42 \mathrm{~g} \mathrm{~m}^{-3}$ and $m_{\mathrm{POM}}$ $=0.126)$ : A) assuming a constant Chl:POM $f$ ratio $=6\left[\mathrm{mg} \mathrm{g}^{-1}\right]$; B) imposing a variable Chl:POM $\mathrm{PO}_{f}$ ratio, $\left.\Theta_{v}=4\left[\mathrm{mg} \mathrm{g}^{-1}\right]+9\left[\mathrm{~m}^{3} \mathrm{~g}^{-1}\right] \times \mathrm{POM}_{f}\left[\mathrm{~g} \mathrm{~m}^{-3}\right] ; \mathrm{C}\right)$ dependency between satellite Chla and total suspended matter (TSM) concentration $\left(\right.$ data $=$ green points, POM-TSM model and constant $\mathrm{Chl}: \mathrm{POM}_{f}$ ratio $=$ gray line, POM-TSM model and variable Chl:POM $f=$ blue line). 


\subsection{Implications for coastal biogeochemistry}

The interpretation of spatio-temporal changes in coastal TSM can be ambiguous, because similar TSM concentrations may arise either from mixing and transport of suspended sediments or from primary produced organic matter in the water column. From the analyzed remote sensing data of the German Bight we discerned qualitatively distinguishable TSM zones for the different seasonal periods. A steep transition from shallow and highly turbid areas to deeper and clearer waters persists through all seasons. The turbid zone stretches along coastal fringes and is largely marked by concentrations of $\mathrm{POM}_{m}$ being much higher than $\mathrm{POM}_{f}$. The attached second zone reveals $\mathrm{POM}_{f}$ concentrations that exceed those of $\mathrm{POM}_{m}$. The transition between these two zones is also characterized by changes in sediment dynamics as well as biogeochemical variables (e.g. Fettweis and Lee, 2017), yielding steepest gradients in nutrients, light availability and phytoplankton concentration, as well as showing strong variations in the chlorophyll-to-carbon ratio due to photoacclimation of the algae out(e.g. Kerimoglu et al., 2017).

The existence of a distinctive transitional zone where coastal, resuspended $\mathrm{POM}_{m}$ can interact with freshly produced $\mathrm{POM}_{f}$ has several biogeochemical implications. Fig.13 illustrates major dependencies between the photoautotrophic production of $\mathrm{POM}_{f}$ within pelagic regions and a residual transport towards shallow coastal areas where it may become remineralized or incorporated into sediments. In the shallow coastal zones, endemic organic matter production takes place in parallel, but the residual transport of $\mathrm{POM}_{f}$ induces an additional influx of organic matter. At the same time, resuspended TSM that contains mineral associated $\mathrm{POM}_{m}$ is transported towards the opposite (offshore) direction. Regions where resuspended $\mathrm{POM}_{m}$ can interact with the fresh, high quality $\mathrm{POM}_{f}$ may thus define potential 
hotspots in biogeochemical cycling. In the following, two major mechanisms of TSM and POM flux will be discussed: i) tidally induced residual transport of TSM to the tidal flats and ii) aggregation and sinking of particles. These interacting mechanisms are assumed to affect and shape the predominant patterns seen in Figs.7, 8 and 9 .

The first mechanism involves the tidal induced, estuary-type net transport of TSM. A potential linkage between a shoreward net POM transport and changes in phosphate concentrations within Wadden Seas areas was described by Postma (1954, 1981). Postma (1984) postulated a line of no return for TSM reaching approximately the offshore salinity maximum. TSM between this line (of no return) and the coast had a high probability to accumulate in the Wadden Sea. A theory that explains the linkage between a net shoreward POM transport and the steepness of nutrient gradients was analysed by Ebenhöh et al. (2004). To date, a shoreward transport and trapping of POM in the shallow near-coastal areas is understood to contribute to the accumulation of sediments by purely physical mechanisms that follow from density-driven estuarine circulation and tidal pumping (e.g. Burchard et al., 2008, 2013). Hofmeister et al. (2017) elaborated the approach of Ebenhöh et al. (2004) and showed that coastal nutrient gradients can be well enhanced through net transport of $\mathrm{POM}_{f}$ nearby the seabed by an estuary-type circulation, as long as horizontal density gradients are present. Their model solution discloses how the efficiency of the net shoreward $\mathrm{POM}_{f}$ transport varies with season. This is reflected by a narrowing of the $\mathrm{POM}_{m}$-dominated zone in summer, as revealed in our study (cf. Fig.9). The net transport of $\mathrm{POM}_{f}$ in the results of Hofmeister et al. (2017) were sensitive to variations of the organic particles' settling velocity. An increase of the settling velocity was shown to increase POM export to the bottom layers, which enhanced 
the coastward flux of $\mathrm{POM}_{f}$ in their simulations.

The second mechanism is associated with the formation of large particle aggregates. The incorporation of $\mathrm{POM}_{f}, \mathrm{POM}_{m}$, together with PIM into particles can be thought of enhancing particle settling velocities, thereby promoting $\mathrm{POM}_{f}$ accumulation at the top of the sediments (Fig.13). Enhanced TSM settling velocities in the coastal transition zone were found in extensive analyses of turbidity profiles from Scanfish campaigns (Maerz et al., 2016). These faster sinking particle aggregates effectively clear the water column from mineral load, which is in line with the fairly narrow transitional zone from highly turbid to clearer pelagic waters seen in our results. A net offshore transport of almost neutrally buoyant POM, as part of the estuary-type circulation, involves unicellular photoautotrophs that likely go through dramatic physiological changes while being advected along strong gradients of nutrients and of light availability. For example, algae can be transported from turbid areas of low light but high nutrient concentrations to deeper pelagic waters of higher irradiance but nutrient depletion. An environmental change of this kind enhances photosynthesis but reduces algal growth (cell division). These conditions typically induce the exudation of dissolved organic, carbon-enriched compounds that can form gel-like particles (e.g. transparent exopolymer particles) (Alldredge et al., 1993; Verdugo et al., 2004; Engel et al., 2004). There is evidence that this gel-like organic matter can mediate aggregates by increasing shear resistance of particles to fragmentation (Maerz and Wirtz, 2009), a process otherwise highly effective in turbulent tidal waters (Fettweis et al., 2014). The increased stickiness of the particles due to the presence of gel-like substances will also contribute to a stabilization of the upper sediment layers (Fang et al., 2014), thus dampening resuspension. In this context it is interesting to notice that the 
1005 estuarine-type circulation should weaken or even may reverse during summer 1006 (Burchard et al., 2008; Flöser et al., 2011) thus creating a reservoir of POM 1007 in the transition zone that may be remobilized and transported towards the 1008 coast during fall.

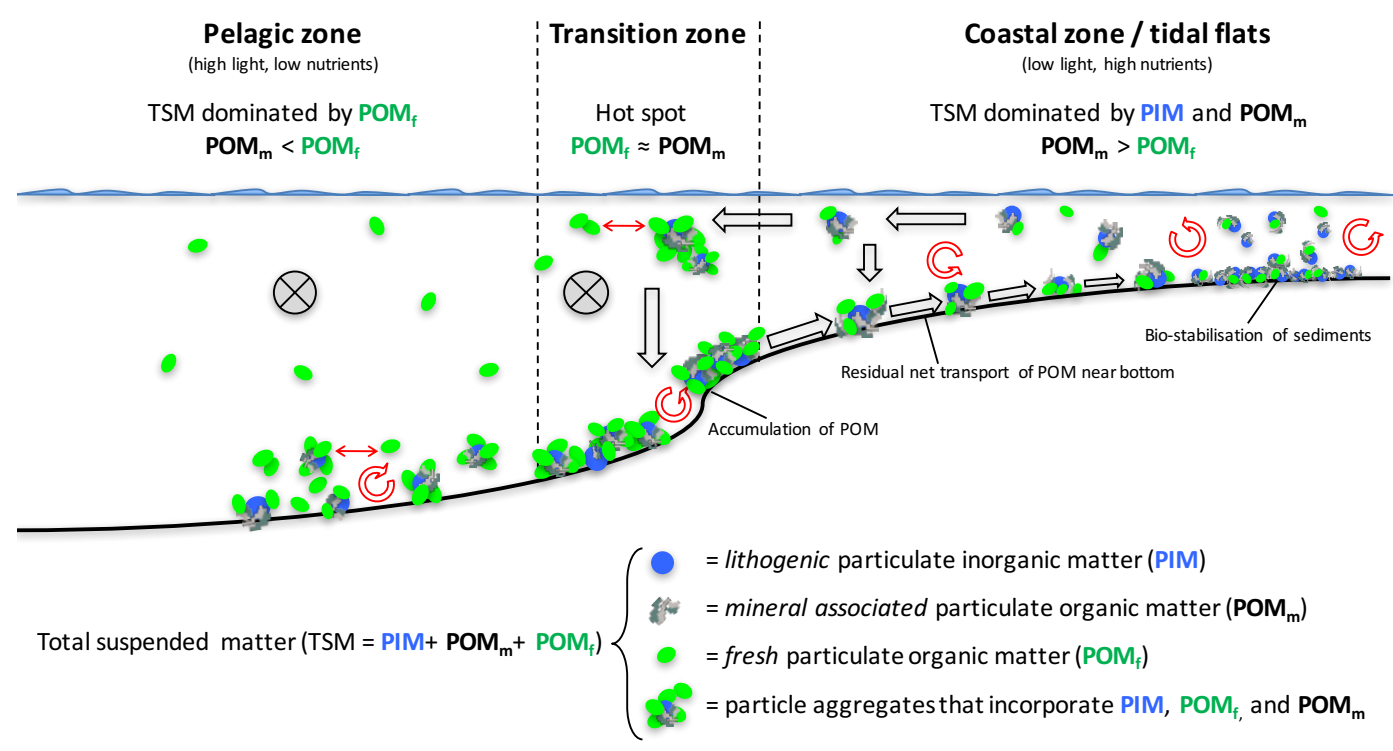

Figure 13: Sketch of the total suspended matter (TSM) transports and particle interaction between shallow coastal and deeper pelagic regions. The crossed circles indicate along-shore currents. Large arrows illustrate the vertical- and cross-sectional net transport pathways of TSM. The associated major mechanisms are i) tidal induced, estuary-type net transport of TSM and ii) the formation of large aggregates that incorporate $\mathrm{POM}_{f}, \mathrm{POM}_{m}$, and PIM. Turbulent mixing and resuspension are depicted as red circles with arrows. The biogeochemical implications are discussed in main text. 


\section{Summary and conclusions}

Water sample data of Loss-on-Ignition (LoI) and corresponding total suspended matter (TSM) measurements were used to devise a semi-empirical model that approximates the fraction of particulate organic matter (POM) at a given TSM concentration. With the POM-TSM model we introduced only two parameters $\left(K_{\mathrm{POM}}\right.$ and $\left.m_{\mathrm{POM}}\right)$ whose values are well identifiable for data that cover TSM concentrations between $\approx 1$ to $\approx 300 \mathrm{~g} \mathrm{~m}^{-3}$. By means of cross-validation we evaluated errors of the POM estimates at low and at high TSM concentrations separately, because these errors may differ considerably $\left(\left|\mathrm{POM}_{\text {obs }}-\mathrm{POM}^{\text {model }}\right|:=\left|e_{\text {res }}\right|<0.5 \mathrm{~g} \mathrm{~m}^{-3}\right.$ for TSM $<10$ $\mathrm{g} \mathrm{m}^{-3}$ and $\left|e_{\text {res }}\right| \approx 1 \mathrm{~g} \mathrm{~m}^{-3}$ for TSM $\left.>10\right)$. In both cases, the respective residual errors are nearly symmetric, without any severe bias. From these results we conclude that the approximations of the POM-TSM model are robust.

Estimates of the parameter $m_{\mathrm{POM}}$ are mainly constrained by LoI data at high TSM concentrations (e.g. $>60 \mathrm{~g} \mathrm{~m}^{-3}$ ) and its value determines the TSM fraction of mineral associated POM $\left(\mathrm{POM}_{m}\right)$. The optimized values of $m_{\text {POM }}$ reveal only small differences between the seasonal data subsets. We argue that variations in $m_{\mathrm{POM}}$ rather express differences in sediment type than seasonal changes. We found significant differences between estimates of $K_{\mathrm{POM}}$ when fitted to the seasonal data subsets. We conclude that estimates of $K_{\mathrm{POM}}$ reflect mainly the seasonally varying build-up and decay of fresh $\mathrm{POM}\left(\mathrm{POM}_{f}\right)$ at TSM concentrations smaller than $60 \mathrm{~g} \mathrm{~m}^{-3}$. According to the POM-TSM model, values assigned to $K_{\mathrm{POM}}$ relative to those of $m_{\mathrm{POM}}$ determine the relative proportions of $\mathrm{POM}_{f}$ to $\mathrm{POM}_{m}$.

We exemplified the suitability of our approach by applying the POM- 
TSM model to remote sensing TSM data of the German Bight. Regional maps of $\mathrm{POM}_{f}$ and $\mathrm{POM}_{m}$ were computed with the calibrated model, which helped identifying coherent, temporal and spatial patterns of qualitative changes in TSM. Differences in concentrations between $\mathrm{POM}_{f}$ and $\mathrm{POM}_{m}$ reveal zonal bands, reflecting areas where either $\mathrm{POM}_{f}$ or $\mathrm{POM}_{m}$ dominate.

The number of distinguishable zonal bands varies with season. The biogeochemical implications of these patterns were discussed and we conclude that the proposed POM-TSM model can be used to detect locations (e.g. hot spots) that remain unresolved by maps of TSM concentration alone.

The POM-TSM model was also tested with measurements collected within other regions (e.g. Limfjorden or Ria de Vigo). We found the $m_{\mathrm{POM}}$ estimates for the German Bight to be portable to other regions. Regional differences and exceptional events, e.g. a Phaeocystis bloom, are well expressed by different values of $K_{\mathrm{POM}}$. In addition, we tested our model against observations of the particulate organic carbon (POC) fraction of TSM. This required only one more parameter $\left(f_{\mathrm{POC}}\right)$ that simply represents the carbon fraction of POM. Based on data of mean POC fractions of TSM, collected world wide, we obtained $f_{\mathrm{POC}}$ to be close to 0.1 , which yields POC fractions of $\approx 10 \%$ at $\mathrm{TSM}<0.3 \mathrm{~g} \mathrm{~m}^{-3}$ and $\approx 1 \%$ at TSM $>300 \mathrm{~g} \mathrm{~m}^{-3}$. Overall, we conclude that the POM-TSM model is generally portable to other coastal environments and may also be used to derive meaningful estimates of POC from TSM concentrations.

\section{Acknowledgements}

We would like to thank the crews of the research vessels "Heincke", "Ludwig Prandtl" and "Storch". We are grateful for the inspiring effort and careful 
1060 work done by the technical staff, who carried out water sampling and lab1061 oratory analysis. We thank the reviewers for their in-depth reviews and 1062 their constructive comments. A suggestion by Markus Pahlow is gratefully 1063 acknowledged, as it helped us with the comparison between model derived 1064 and remote sensing chlorophyll $a$ concentrations. 


\section{References}

Alldredge, A. L., Passow, U., Logan, B. E., Howarth, M., 1993. The abundance and significance of a class of large, transparent organic particles in the ocean. Deep Sea Research Part I: Oceanographic Research Papers 40 (6), 1131 - 1140.

URL http://www.sciencedirect.com/science/article/pii/096706379390129Q

Arnarson, T. S., Keil, R. G., 2001. Organic-mineral interactions in marine sediments studied using density fractionation and x-ray photoelectron spectroscopy. Organic Geochemistry 32 (12), 1401-1415.

Arnarson, T. S., Keil, R. G., 2007. Changes in organic matter-mineral interactions for marine sediments with varying oxygen exposure times. Geochimica et Cosmochimica Acta 71 (14), 3545-3556.

Babin, M., Stramski, D., 2004. Variations in the mass-specific absorption coefficient of mineral particles suspended in water. Limnology and Oceanography $49(3), 756-767$.

Bale, A., Morris, A., 1998. Organic carbon in suspended particulate material in the North Sea: Effect of mixing resuspended and background particles. Continental Shelf Research 18 (11), 1333-1345.

Balls, P., 1990. Distribution and composition of suspended particulate material in the clyde estuary and associated sea lochs. Estuarine, Coastal and Shelf Science 30 (5), 475-487.

Barillé-Boyer, A.-L., Barillé, L., Massé, H., Razet, D., Héral, M., 2003. Correction for particulate organic matter as estimated by loss on ignition in estuarine ecosystems. Estuarine, Coastal and Shelf Science 58 (1), 147 
$-153$.

URL http://www.sciencedirect.com/science/article/pii/S0272771403000696

Brzezinski, M. A., 1985. The Si:C:N ratio of marine diatoms: interspecific variability and the effect of some environmental variables. Journal of Phycology 21 (3), 347-357.

Burchard, H., Flöser, G., Staneva, J. V., Badewien, T. H., Riethmöller, R., Chen, C., 2008. Impact of density gradients on net sediment transport into the wadden sea. Journal of Physical Oceanography 38 (3), 566-587. URL https://doi.org/10.1175/2007JP03796.1

Burchard, H., Schuttelaars, H. M., Geyer, W. R., Babin, M., 2013. Residual sediment fluxes in weakly-to-periodically stratified estuaries and tidal inlets. Journal of Physical Oceanography 43 (9), 1841-1861.

URL https://doi.org/10.1175/JPO-D-12-0231.1

Cloern, J., Foster, S., Kleckner, A., 2014. Phytoplankton primary production in the world's estuarine-coastal ecosystems. Biogeosciences 11 (9), $2477-2501$.

Comber, S., Gardner, M., Gunn, A., Whalley, C., 1996. Kinetics of trace metal sorption to estuarine suspended particulate matter. Chemosphere 33 (6), 1027-1040.

Daphne, L. H. X., Utomo, H. D., Kenneth, L. Z. H., 2011. Correlation between turbidity and total suspended solids in Singapore rivers. Journal of Water Sustainability 1 (3), 313-322.

Doerffer, R., May 2011. Alternative atmospheric correction procedure for Case 2 water remote sensing using MERIS. Tech. rep., ESA Earth Online. 
Doerffer, R., Schiller, H., 2007. The MERIS Case 2 water algorithm. International Journal of Remote Sensing 28 (3-4), 517-535.

Ebenhöh, W., Kohlmeier, C., Baretta, J. W., Flöser, G., 2004. Shallowness may be a major factor generating nutrient gradients in the wadden sea. Ecological Modelling 174 (3), 241 - 252.

URL http://www.sciencedirect.com/science/article/pii/S0304380003004277

Eisma, D., 1981. The mass-balance of suspended matter and associated pollutants in the North Sea. Rapp. P.-v. Reun. Cons. int. Explor. Mer 181, $7-14$.

Eisma, D., Irion, G., 1988. Suspended matter and sediment transport. In: Pollution of the North Sea. Springer, pp. 20-35.

Eisma, D., Kalf, J., 1987. Distribution, organic content and particle size of suspended matter in the North Sea. Netherlands Journal of Sea Research $21(4), 265-285$.

Engel, A., Thoms, S., Riebesell, U., Rochelle-Newall, E., Zondervan, I., 04 2004. Polysaccharide aggregation as a potential sink of marine dissolved organic carbon. Nature 428, $929 \mathrm{EP}-$.

URL http://dx.doi.org/10.1038/nature02453

Fang, H., Shang, Q., Chen, M., He, G., Comber, S., 2014. Changes in the critical erosion velocity for sediment colonized by biofilm. Sedimentology $61(3), 648-659$.

URL http://dx.doi.org/10.1111/sed.12065

Fettweis, M., Baeye, M., 2015. Seasonal variation in concentration, size, and 
settling velocity of muddy marine flocs in the benthic boundary layer. Journal of Geophysical Research: Oceans 120 (8), 5648-5667.

Fettweis, M., Baeye, M., Van der Zande, D., Van den Eynde, D., Joon Lee, B., 2014. Seasonality of floc strength in the southern north sea. Journal of Geophysical Research: Oceans 119 (3), 1911-1926.

URL http://dx.doi.org/10.1002/2013JC009750

Fettweis, M., Lee, B. J., 2017. Spatial and seasonal variation of biomineral suspended particulate matter properties in high-turbid nearshore and lowturbid offshore zones. Water 9 (9).

Fettweis, M., Nechad, B., Van den Eynde, D., 2007. An estimate of the suspended particulate matter (SPM) transport in the southern North Sea using SeaWiFS images, in situ measurements and numerical model results. Continental Shelf Research 27 (10), 1568-1583.

Figge, K., 1981. Karte der sedimentverteilung in der deutschen bucht, nordsee. Karte nr. 2900, Deutsches Hydrographisches Institut, Hamburg.

Flemming, B. W., Delafontaine, M. T., 2000. Mass physical properties of muddy intertidal sediments: some applications, misapplications and non-applications. Continental Shelf Research 20 (10), 1179 - 1197.

URL http://www.sciencedirect.com/science/article/pii/S0278434300000182

Flemming, B. W., Nyandwi, N., Sep 1994. Land reclamation as a cause of fine-grained sediment depletion in backbarrier tidal flats (southern north sea). Netherland Journal of Aquatic Ecology 28 (3), 299-307.

URL https://doi.org/10.1007/BF02334198 
Flöser, G., Burchard, H., Riethmüller, R., 2011. Observational evidence for estuarine circulation in the German Wadden Sea. Continental Shelf Research 31 (16), 1633 - 1639.

URL http://www.sciencedirect.com/science/article/pii/S0278434311001257

Fry, B., 2013. Alternative approaches for solving underdetermined isotope mixing problems. Marine ecology progress series 472, 1-13.

Garnier, J.-M., Ciffroy, P., Benyahya, L., 2006. Implications of short and long term (30 days) sorption on the desorption kinetic of trace metals (cd, zn, co, mn, fe, ag, cs) associated with river suspended matter. Science of the Total Environment 366 (1), 350-360.

Geider, R. J., La Roche, J., 2002. Redfield revisited: variability of c:n:p in marine microalgae and its biochemical basis. European Journal of Phycology 37 (1), 1-17.

Hering, D., Borja, A., Carstensen, J., Carvalho, L., Elliott, M., Feld, C. K., Heiskanen, A.-S., Johnson, R. K., Moe, J., Pont, D., Solheim, A. L., van de Bund, W., 2010. The european water framework directive at the age of 10: A critical review of the achievements with recommendations for the future. Science of The Total Environment 408 (19), 4007 - 4019. URL http://www.sciencedirect.com/science/article/pii/S0048969710005462

Herman, P. M., 2006. Managing benthic ecosystems in relation to physical forcing and environmental constraints - mabene. Final report pp. 101, EU contract EVK3-CT-2002-0007.

Hofmeister, R., Flöser, G., Schartau, M., Apr 2017. Estuary-type circulation as a factor sustaining horizontal nutrient gradients in freshwater- 
influenced coastal systems. Geo-Marine Letters 37 (2), 179-192.

URL https://doi.org/10.1007/s00367-016-0469-z

Hommersom, A., Peters, S., Wernand, M. R., de Boer, J., 2009. Spatial and temporal variability in bio-optical properties of the Wadden Sea. Estuarine, Coastal and Shelf Science 83 (3), 360-370.

Irion, G., Zöllmer, V., 1999. Clay mineral associations in fine-grained surface sediments of the north sea. Journal of Sea Research 41 (1), 119-128.

Ittekkot, V., 1988. Global trends in the nature of organic matter in river suspensions. Nature 332, 436-438.

Ittekkot, V., Laane, R. W., 01 1991. Fate fo riverine particulate organic matter. In: E.T. Degens, S. Kempe, J. R. (Ed.), Biogeochemistry of Major World Rivers, Scope 42. John Wiley and Sons, Ltd, Chichester, Ch. 10, pp. 233-243.

Jago, C., Bale, A., Green, M., Howarth, M., Jones, S., McCave, I., Millward, G., Morris, A., Rowden, A., Williams, J., et al., 1993. Resuspension Processes and Seston Dynamics, Southern North Sea [and discussion]. Philosophical Transactions of the Royal Society of London. Series A: Physical and Engineering Sciences 343 (1669), 475-491.

Jakobsen, H. H., Markager, S., 2016. Carbon-to-chlorophyll ratio for phytoplankton in temperate coastal waters: Seasonal patterns and relationship to nutrients. Limnology and Oceanography 61 (5), 1853-1868.

URL https://aslopubs . onlinelibrary.wiley.com/doi/abs/10.1002/lno.10338

Kallis, G., Butler, D., 2001. The eu water framework directive: measures 
and implications. Water Policy 3 (2), $125-142$.

URL http://www.sciencedirect.com/science/article/pii/S1366701701000071

Keil, R. G., Montluçon, D. B., Prahl, F. G., Hedges, J. I., 1994. Sorptive preservation of labile organic matter in marine sediments. Nature 370, $549-552$.

Kerimoglu, O., Hofmeister, R., Maerz, J., Riethmüller, R., Wirtz, K. W., 2017. The acclimative biogeochemical model of the southern North Sea. Biogeosciences 14 (19).

Liénart, C., Savoye, N., Bozec, Y., Breton, E., Conan, P., David, V., Feunteun, E., Grangeré, K., Kerherv'e, P., Lebreton, B., Lefebvre, S., L'Helguen, S., Mousseau, L., Raimbault, P., Richard, P., Riera, P., Sauriau, P.-G., Schaal, G., Aubert, F., Aubin, S., Bichon, S., Boinet, C., Bourasseau, L., Bréret, M., Caparros, J., Cariou, T., Charlier, K., Claquin, P., Cornille, V., Corre, A.-M., Costes, L., Crispi, O., Crouvoisier, M., Czamanski, M., Amo, Y. D., Derriennic, H., Dindinaud, F., Durozier, M., Hanquiez, V., Nowaczyk, A., Devesa, J., Ferreira, S., Fornier, M., Garcia, F., Garcia, N., Geslin, S., Grossteffan, E., Gueux, A., Guillaudeau, J., Guillou, G., Joly, O., Lachaussée, N., Lafont, M., Lamoureux, J., Lecuyer, E., Lehodey, J.-P., Lemeille, D., Leroux, C., Macé, E., Maria, E., Pineau, P., Petit, F., Pujo-Pay, M., Rimelin-Maury, P., Sultan, E., 2017. Dynamics of particulate organic matter composition in coastal systems: A spatio-temporal study at multi-systems scale. Progress in Oceanography 156 (Supplement C), 221 - 239.

URL http://www.sciencedirect.com/science/article/pii/S0079661116301914

Maerz, J., Hofmeister, R., van der Lee, E. M., Gräwe, U., Riethmüller, R., 
Wirtz, K. W., 2016. Maximum sinking velocities of suspended particulate matter in a coastal transition zone. Biogeosciences 13 (17), 4863-4876.

URL https://www.biogeosciences.net/13/4863/2016/

Maerz, J., Wirtz, K. W., 2009. Resolving physically and biologically driven suspended particulate matter dynamics in a tidal basin with a distribution-based model. Estuarine, Coastal and Shelf Science 84 (1), $128-138$.

URL http://www.sciencedirect.com/science/article/pii/S0272771409002522

Manheim, F. T., Hathaway, J. C., Uchupi, E., 1972. Suspended matter in surface waters of the northern gulf of mexico1. Limnology and Oceanography 17 (1), 17-27.

URL http://dx.doi.org/10.4319/1o.1972.17.1.0017

Martinez-Vicente, V., Land, P. E., Tilstone, G. H., Widdicombe, C., Fishwick, J. R., 2010. Particulate scattering and backscattering related to water constituents and seasonal changes in the Western English Channel. Journal of Plankton Research 32 (5), 603-619.

Mayer, L. M., 1994. Surface area control of organic carbon accumulation in continental shelf sediments. Geochimica et Cosmochimica Acta 58 (4), $1271-1284$.

Meybeck, M., 1982. Carbon, nitrogen, and phosphorus transport by world rivers. Am. J. Sci 282 (4), 401-450.

Middelburg, J. J., Herman, P. M., 2007. Organic matter processing in tidal estuaries. Marine Chemistry 106 (1), 127-147. 
Mobley, C. D., Sundman, L. K., October 2013. Hydrolight 5.2-ecolight 5.2. Technical documentation, Sequoia Scientific Inc., Bellevue, WA, USA.

Morris, A., Bale, A., Howland, R., Loring, D., Rantala, R., 1987. Controls of the chemical composition of particle populations in a macrotidal estuary (Tamar estuary, UK). Continental Shelf Research 7 (11), 1351-1355.

Nyeffeler, U., Li, Y., Santschi, P., 1984. A kinetic approach to describe traceelement distribution bewteen particles and solution in natural aquatic systems. Geochim Cosmochim Acta 48 (1), 513-1.

Ouillon, S., Douillet, P., Petrenko, A., Neveux, J., Dupouy, C., Froidefond, J.-M., Andréfouët, S., Muñoz-Caravaca, A., 2008. Optical algorithms at satellite wavelengths for total suspended matter in tropical coastal waters. Sensors 8 (7), 4165-4185.

URL http://www.mdpi.com/1424-8220/8/7/4165

Petus, C., Chust, G., Gohin, F., Doxaran, D., Froidefond, J.-M., Sagarminaga, Y., 2010. Estimating turbidity and total suspended matter in the adour river plume (south bay of biscay) using modis 250-m imagery. Continental Shelf Research 30 (5), 379 - 392.

URL http://www.sciencedirect.com/science/article/pii/S0278434309003689

Postma, H., 1954. Hydrography of the Dutch Wadden Sea: A study of the relations between water movement, the transport of suspended materials and the production of organic matter. Archives Zoological Station Den Helder of the Netherland's Zoological Society, 405-511.

Postma, H., 1981. Exchange of materials between the North Sea and the Wadden Sea. Marine Geology 40 (1), 199-213. 
Postma, H., 1984. Introduction to the symposium on organic matter in the wadden sea. Neth. Inst. Sea Res. Publ. Ser 10, 15-22.

Puls, W., Heinrich, H., Mayer, B., 1997. Suspended particulate matter budget for the German Bight. Marine Pollution Bulletin 34 (6), 398-409.

Rick, H. J., Rick, S., Tillmann, U., Brockmann, U., Gärtner, U., Dürselen, C., Sündermann, J., Feb 2006. Primary productivity in the german bight (1994-1996). Estuaries and Coasts 29 (1), 4-23.

URL https://doi.org/10.1007/BF02784695

Riethmüller, R., Flöser, G., 2017. Suspended particulate matter concentrations and organic matter fractions from water samples. PANGAEA, https://doi.org/10.1594/PANGAEA.882561.

Riethmüller, R., Heineke, M., Kühl, H., Keuker-Rüdiger, R., 2000. Chlorophyll a concentration as an index of sediment surface stabilisation by microphytobenthos? Continental Shelf Research 20 (10), 1351-1372.

Ríos, A. F., Fraga, F., Pérez, F. F., Figueiras, F. G., et al., 1998. Chemical composition of phytoplankton and particulate organic matter in the Ría de Vigo (NW Spain). Scientia Marina 62 (3), 257-271.

Röttgers, R., Heymann, K., Krasemann, H., 2014. Suspended matter concentrations in coastal waters: Methodological improvements to quantify individual measurement uncertainty. Estuarine, Coastal and Shelf Science 151, $148-155$.

URL http://www.sciencedirect.com/science/article/pii/S0272771414002984

Rusch, A., Huettel, M., 2000. Advective particle transport into permeable sediments, evidence from experiments in an intertidal sandflat. Limnology 
and Oceanography $45(3), 525-533$.

URL http://dx.doi.org/10.4319/10.2000.45.3.0525

Sempéré, R., Charrière, B., Van Wambeke, F., Cauwet, G., 2000. Carbon inputs of the Rhone River to the Mediterranean Sea: biogeochemical implications. Global Biogeochemical Cycles 14 (2), 669-681.

Smith, S., Renwick, W., Buddemeier, R., Crossland, C., 2001. Budgets of soil erosion and deposition for sediments and sedimentary organic carbon across the conterminous United States. Global Biogeochemical Cycles $15(3), 697-707$.

Stavn, R. H., Richter, S. J., 2008. Biogeo-optics: particle optical properties and the partitioning of the spectral scattering coefficient of ocean waters. Applied optics 47 (14), 2660-2679.

Sundby, B., 1974. Distribution and transport of suspended particulate matter in the Gulf of St. Lawrence. Canadian Journal of Earth Sciences 11 (11), 1517-1533.

Sundby, B., Gobeil, C., Silverberg, N., Alfonso, M., 1992. The phosphorus cycle in coastal marine sediments. Limnology and oceanography 37 (6), $1129-1145$.

Uncles, R. J., Stephens, J. A., Harris, C., 2006. Properties of suspended sediment in the estuarine turbidity maximum of the highly turbid Humber Estuary system, UK. Ocean Dynamics 56 (3-4), 235-247.

van Beusekom, J. E., Loebl, M., Martens, P., 2009. Distant riverine nutrient supply and local temperature drive the long-term phytoplankton development in a temperate coastal basin. Journal of Sea Research 61 (1), 26-33. 
Van Beusekom, J. E. E., Brockmann, U. H., 1998. Transformation of phosphorus in the Elbe estuary. Estuaries 21 (4), 518-526.

Van Beusekom, J. E. E., De Jonge, V. N., 2002. Long-term changes in wadden sea nutrient cycles: importance of organic matter import from the north sea. Hydrobiologia 475 (1), 185-194.

Verdugo, P., Alldredge, A. L., Azam, F., Kirchman, D. L., Passow, U., Santschi, P. H., 2004. The oceanic gel phase: a bridge in the dom-pom continuum. Marine Chemistry 92 (1), 67 - 85, new Approaches in Marine Organic Biogeochemistry: A Tribute to the Life and Science of John I. Hedges.

URL http://www.sciencedirect.com/science/article/pii/S0304420304001951

Wang, A.-J., Ye, X., Liu, J. T., Xu, Y.-H., Yin, X.-J., Xu, X.-H., 2017. Sources of settling particulate organic carbon during summer in the northern taiwan strait. Estuarine, Coastal and Shelf Science 198, 487 496.

URL http://www.sciencedirect.com/science/article/pii/S0272771416304371

Wang, Q., Li, Y., Wang, Y., 2011. Optimizing the weight loss-on-ignition methodology to quantify organic and carbonate carbon of sediments from diverse sources. Environmental Monitoring and Assessment 174 (1), 241257.

URL https://doi.org/10.1007/s10661-010-1454-z

Woźniak, S. B., 2014. Simple statistical formulas for estimating biogeochemical properties of suspended particulate matter in the southern baltic sea potentially useful for optical remote sensing applications. Oceanologia $56(1), 7-39$. 
1351 Zhang, X., Stavn, R. H., Falster, A. U., Gray, D., Gould, R. W., 2014. New

1352 insight into particulate mineral and organic matter in coastal ocean waters

1353 through optical inversion. Estuarine, Coastal and Shelf Science 149, 1-12. 


\section{Appendix A. Procedure to derive total suspended matter (TSM) concentrations in Case-2 waters from remote sensing}

The procedure for deriving TSM concentrations from remote sensing signals in Case-2 waters is fully described in Doerffer and Schiller (2007) and Doerffer (2011). The procedure refers to the application of the C2R (Case-2 Regional processor, version 1.6.2, 2010), where the atmospheric correction is based on a neural network trained with simulated reflectances.

The basic idea is to associate water leaving reflectances and path reflectances with top of atmosphere reflectances for a large number of different cases of solar and viewing angles, concentrations of different aerosols, concentrations of optical components in water and wind speeds for simulated sky and sun glint. These associations are manifested in a set of neural networks: Mainly one for the atmospheric part and one for the in-water part. Supplementary are networks for out-of-scope and error estimation. They are used for flagging of usable data. Twelve of fifteen MERIS bands (top of atmosphere radiance) are considered: 412, 443, 489, 510, 560, 620, 665, 681, $709,754,779$, and $865 \mathrm{~nm}$. The two infrared bands at 779 and $865 \mathrm{~nm}$ are important for atmospheric correction but are not used for the subsequent in-water retrieval. To obtain these neural nets an extensive dataset of several hundred thousand cases is necessary for training. Such a dataset can only be achieved by simulations.

The radiative transfer simulations for the atmosphere, Fresnel reflectance and more effects at the water surface, and for a first guess of the water reflectance were done with the help of a Monte Carlo photon tracing program. The full simulation of the radiative transfer in the water was performed with HydroLight (Mobley and Sundman, 2013), connecting water leaving 
1400 According to this first step, the observational error $\left(\sigma_{\mathrm{SV}}^{\text {obs }}\right)_{i}$ contains constant 1401 (total) variances $\left.\left(\sigma_{\text {total }}^{2}\right)_{j}\right)$ for every $j$ 'th interval. These (interval specific)

$$
\sigma_{i}^{2}=\left(\sigma_{\text {total }}^{2}\right)_{i}=\left(\sigma_{\text {method }}^{2}\right)_{i}+\left(\sigma_{\mathrm{SV}}^{2}\right)_{i}
$$

The collected LoI data thus involve uncertainties that are independent of methodological errors. For data with known methodological errors we can retrieve information about $\sigma_{\mathrm{SV}}^{2}$ by calculating variances (standard errors) of LoI within specified intervals (ranges) of TSM concentrations in a first step. For single intervals (indexed by $j$ ) the observational error can then be computed as follows:

$$
\left(\sigma_{\mathrm{SV}}^{\mathrm{obs}}\right)_{i}=\sqrt{\left(\sigma_{\text {total }}^{2}\right)_{j}-\left(\sigma_{\text {method }}^{2}\right)_{i}}
$$



1415 model estimate $\left(\sigma_{\mathrm{SV}}^{\text {est }}\right)_{i}$ :

$$
\mathrm{RMS}=\sqrt{\frac{1}{N} \sum_{i=1}^{N}\left(\sigma_{\mathrm{SV}}^{\mathrm{obs}}-\sigma_{\mathrm{SV}}^{\mathrm{est}}\right)_{i}^{2}}
$$

1416 For the LoI data considered in our analyses we obtained: argmin RMS : a ${ }_{1417}=8.75 \mathrm{~g} \mathrm{~m}^{-3}, \epsilon_{\mathrm{lt} 3}=7.3 \%, \epsilon_{\mathrm{gt} 300}=2.9 \%$. Results of of the calibrated 1418 error model (Equation B.3), the final values of $\sigma_{i}^{2}$ together with $\sigma_{\text {method }}^{2}$ are 1419 depicted in Figure B.1. We disregard $\sigma_{\mathrm{SV}}$ for cases where $\sigma_{\mathrm{SV}}^{2}<\sigma_{\text {method }}^{2}$ and 1420 the total error is then set equal to the methodological error $\left(\sigma_{i}^{2}=\sigma_{\text {method }}^{2}\right)$. 

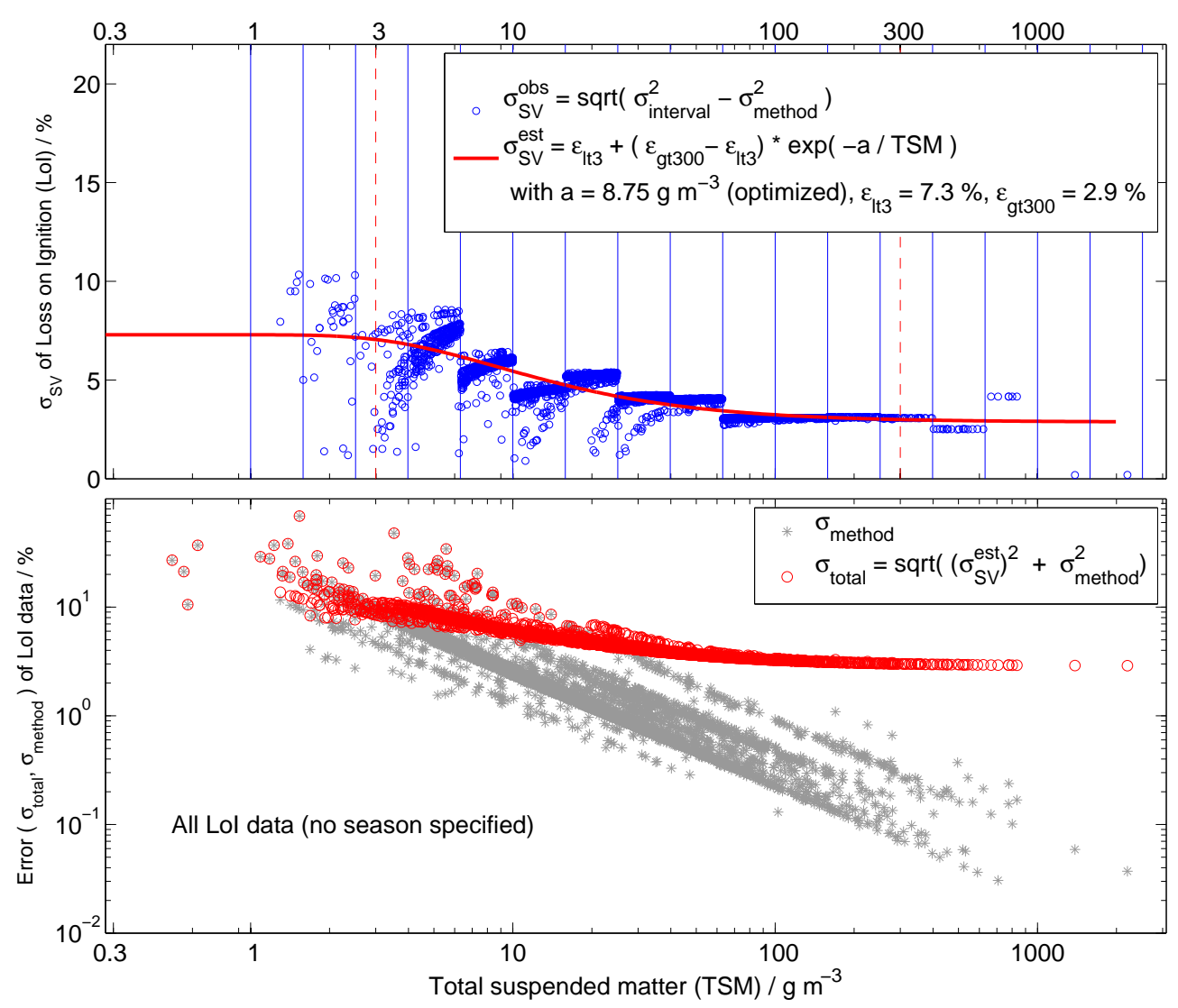

Figure B.1: Approximation of the (system inherent) observational error $\sigma_{\mathrm{SV}}$ (top panel). The TSM concentration range is split up into intervals of equal logarithmic scale. For each interval the system inherent observational error is calculated by subtracting the variance of the data within the interval (reflecting the full variability) from each variance obtained from methodological uncertainties. These so derived system inherent observational errors were then used to fit a continuous error function that can finally be applied to all data individually (thereby minimising a bias effect due to the number and width of selected intervals). Note that, if only methodological errors were considered for Maximum Likelihood (ML) estimation of the POM-TSM model parameters, then high TSM measurements would entirely determine the ML estimates. 
${ }_{1421}$ This may occur in certain cases for TSM concentrations $<10 \mathrm{~g} \mathrm{~m}^{-3}$. For

1422 TSM concentrations above $50 \mathrm{~g} \mathrm{~m}^{-3}$ we typically find $\sigma_{\mathrm{SV}}^{2}>\sigma_{\text {method }}^{2}$ and the ${ }_{1423}$ variances $\sigma_{i}^{2}$ thus ultimately reflect spatio-temporal variability in sampling. 1431 signal.

$$
\begin{aligned}
\mathrm{LoI} & =f_{0}\left(\frac{\mathrm{POM}_{f}}{\mathrm{TSM}}\right)+\left(1-f_{0}\right)\left(\frac{\mathrm{POM}_{m}}{\mathrm{TSM}}\right) \\
& =f_{0}\left(\frac{K_{\mathrm{POM}}}{K_{\mathrm{POM}}+\mathrm{TSM}}\right)+\left(1-f_{0}\right) \cdot m_{\mathrm{POM}}(1-\mathrm{LoI})
\end{aligned}
$$

1432 Solving Equation C.1 for LoI gives us finally:

$$
\begin{aligned}
\mathrm{LoI}= & \frac{\left(f_{0} \cdot K_{\mathrm{POM}}\right)}{K_{\mathrm{POM}}+\mathrm{TSM}} \cdot \frac{1}{1+m_{\mathrm{POM}}-\left(f_{0} \cdot m_{\mathrm{POM}}\right)} \\
& +\frac{m_{\mathrm{POM}}-\left(f_{0} \cdot m_{\mathrm{POM}}\right)}{1+m_{\mathrm{POM}}-\left(f_{0} \cdot m_{\mathrm{POM}}\right)}
\end{aligned}
$$

1433 Equation C.2 reveals that the mixing parameter $f_{0}$ only appears in combi1434 nation with either of the other parameters, $\left(f_{0} \cdot K_{\mathrm{POM}}\right)$ and $\left(f_{0} \cdot m_{\mathrm{POM}}\right)$. 
Appendix D. Supplementary material

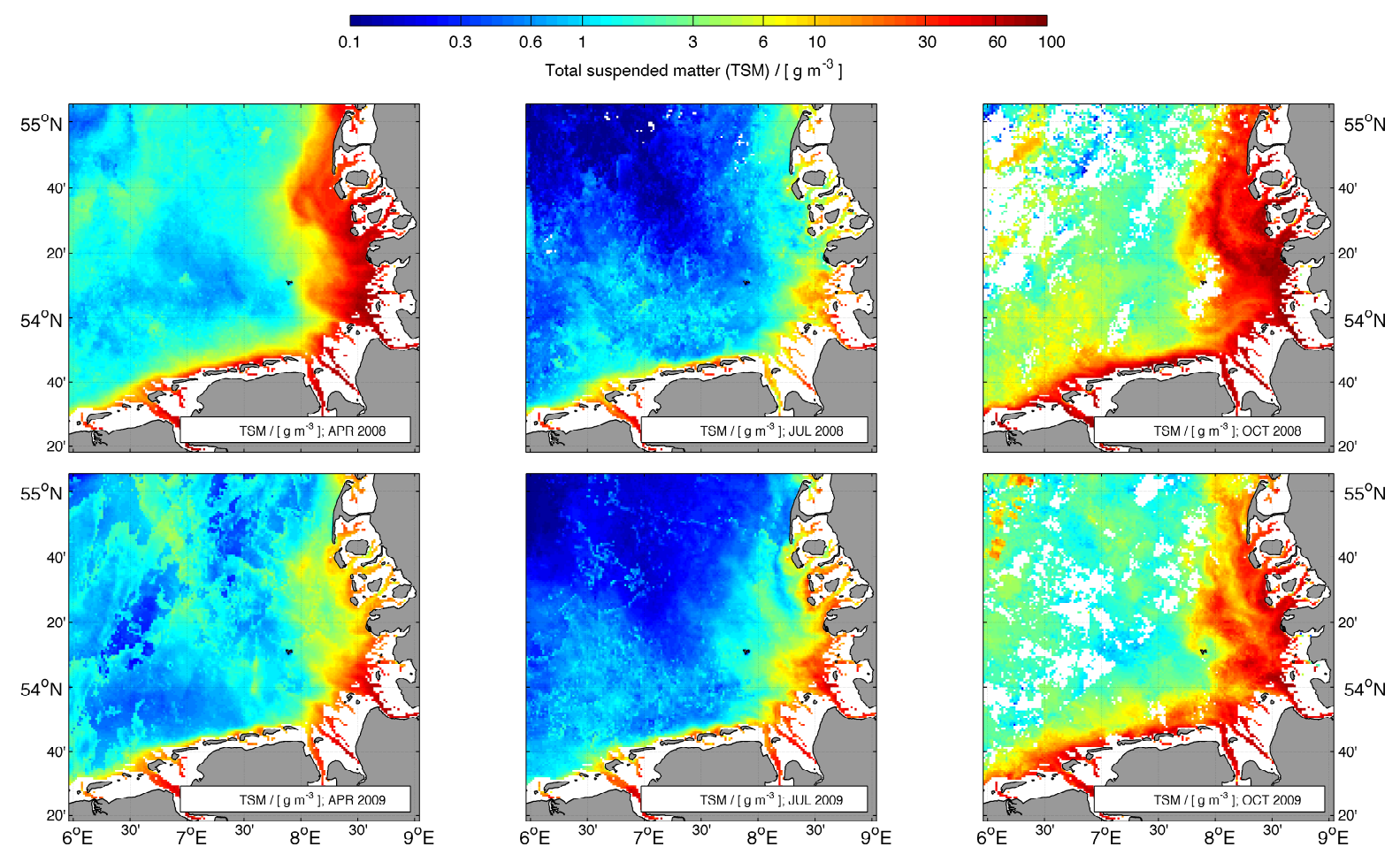

Figure S1: Monthly mean total suspended matter (TSM) concentrations derived from MERIS remote sensing data; comparison between two years (2008, upper panel and 2009 lower panel) for selected months (April, left; July, middle; October, right). 


\begin{tabular}{|c|c|c|c|c|c|c|c|c|}
\hline 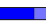 & & 1 & 1 & 1 & $\perp$ & $\perp$ & 1 & \\
\hline 10 & 20 & 30 & 40 & 50 & 60 & 70 & 80 & 90 \\
\hline
\end{tabular}
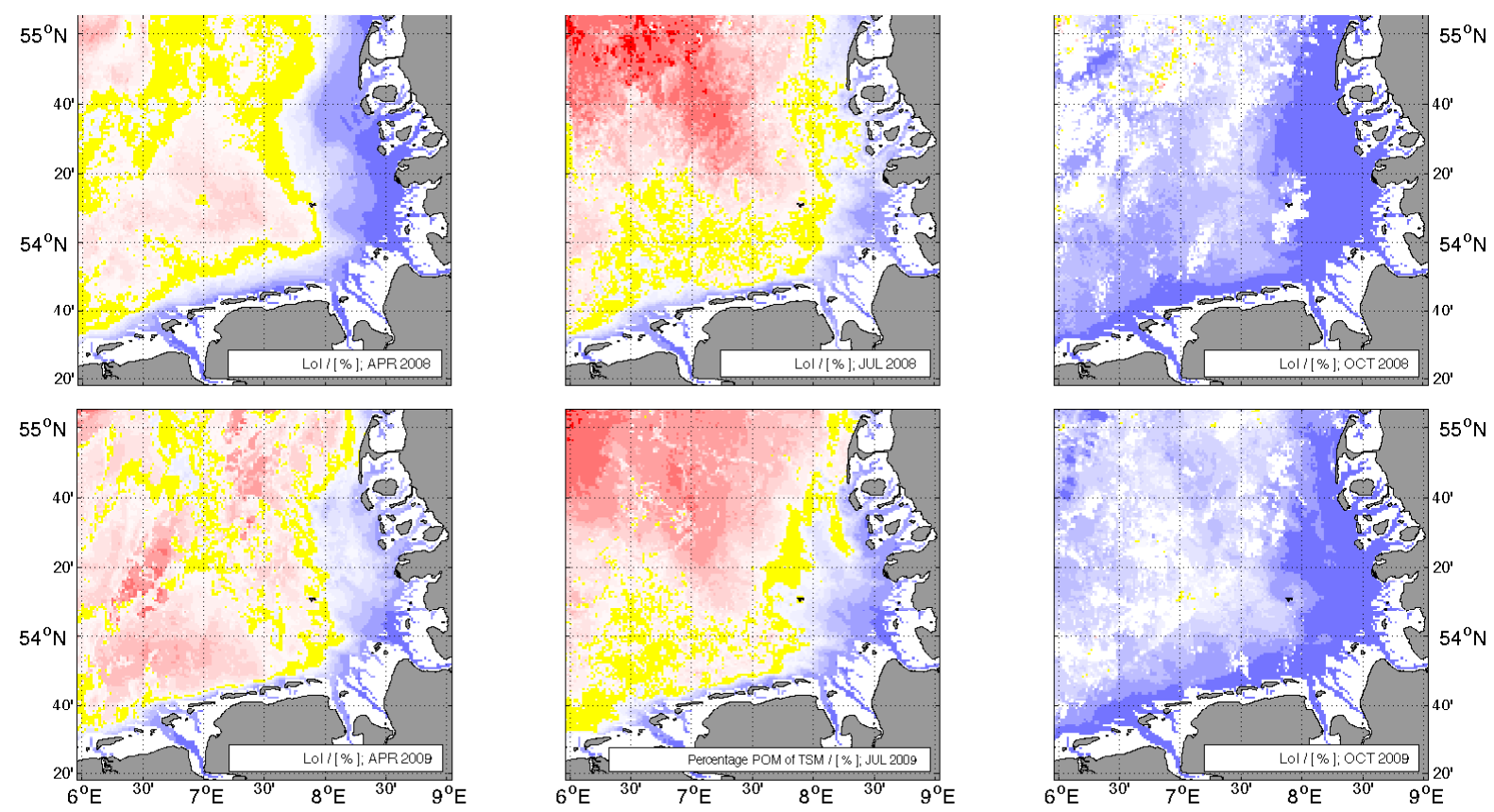

Figure S2: Organic matter fraction of total suspended matter (TSM), based on monthly mean MERIS remote sensing data, calculated with the calibrated POM-TSM model; comparison between two years (2008, upper panel and 2009 lower panel) for selected months (April, left; July, middle; October, right). 


\begin{tabular}{|c|c|c|c|c|c|c|c|c|}
\hline 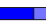 & & 1 & 1 & 1 & $\perp$ & $\perp$ & 1 & \\
\hline 10 & 20 & 30 & 40 & 50 & 60 & 70 & 80 & 90 \\
\hline
\end{tabular}
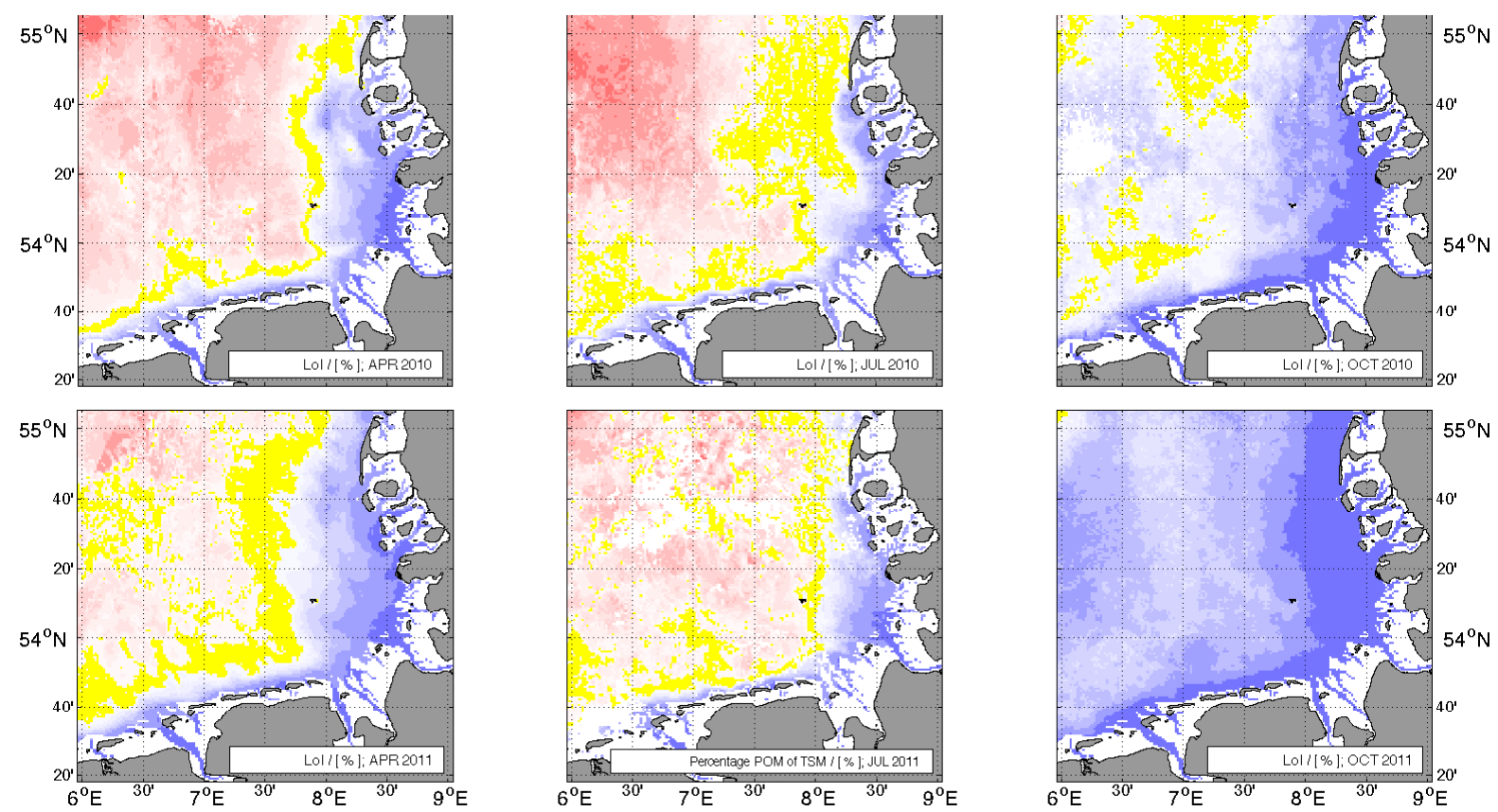

Figure S3: Organic matter fraction of total suspended matter (TSM), based on monthly mean MERIS remote sensing data, calculated with the calibrated POM-TSM model; comparison between two years (2010, upper panel and 2011 lower panel) for selected months (April, left; July, middle; October, right). 


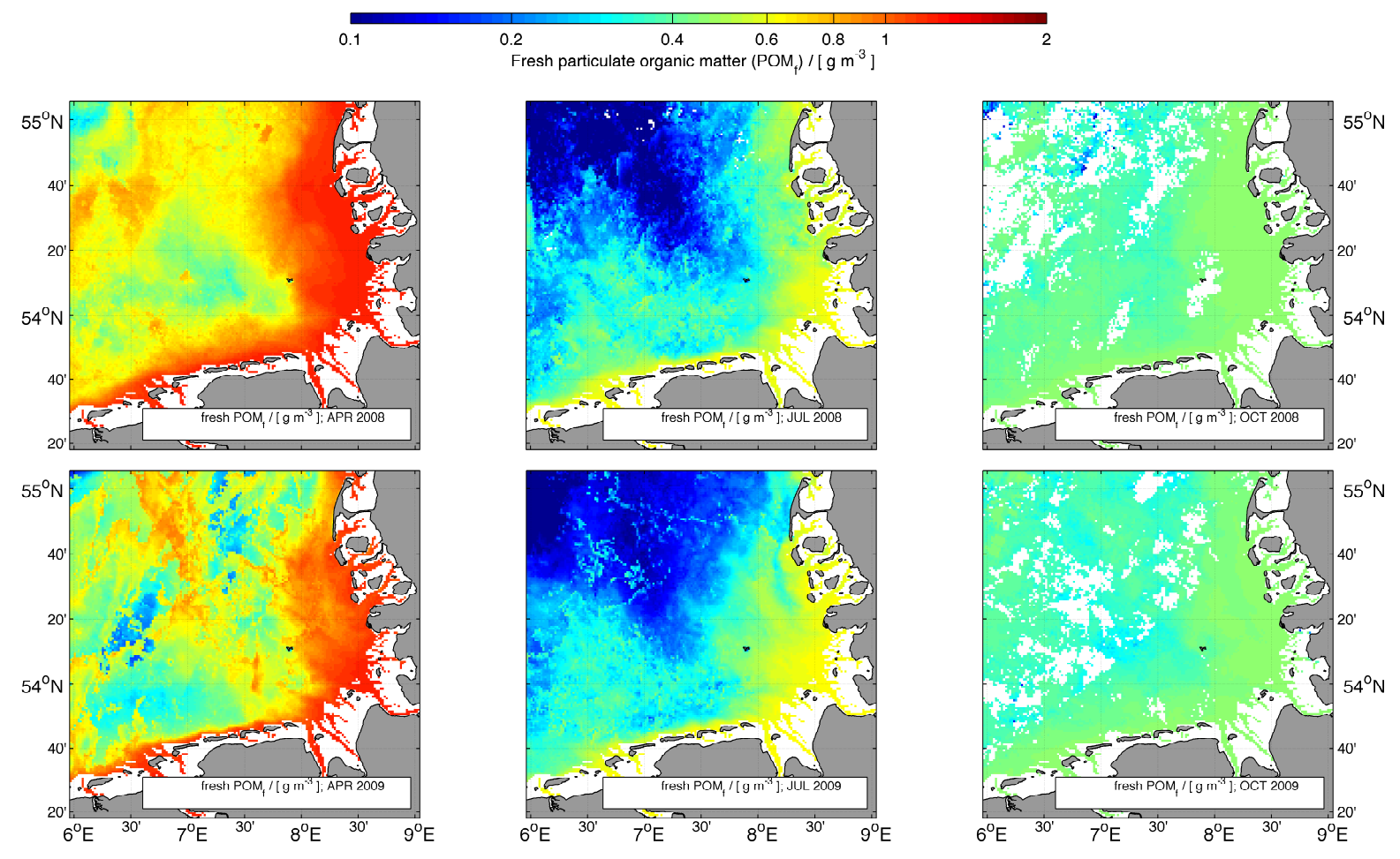

Figure S4: Organic matter fraction of total suspended matter (TSM), based on monthly mean MERIS remote sensing data, calculated with the calibrated POM-TSM model; comparison between two years (2008, upper panel and 2009 lower panel) for selected months (April, left; July, middle; October, right). 


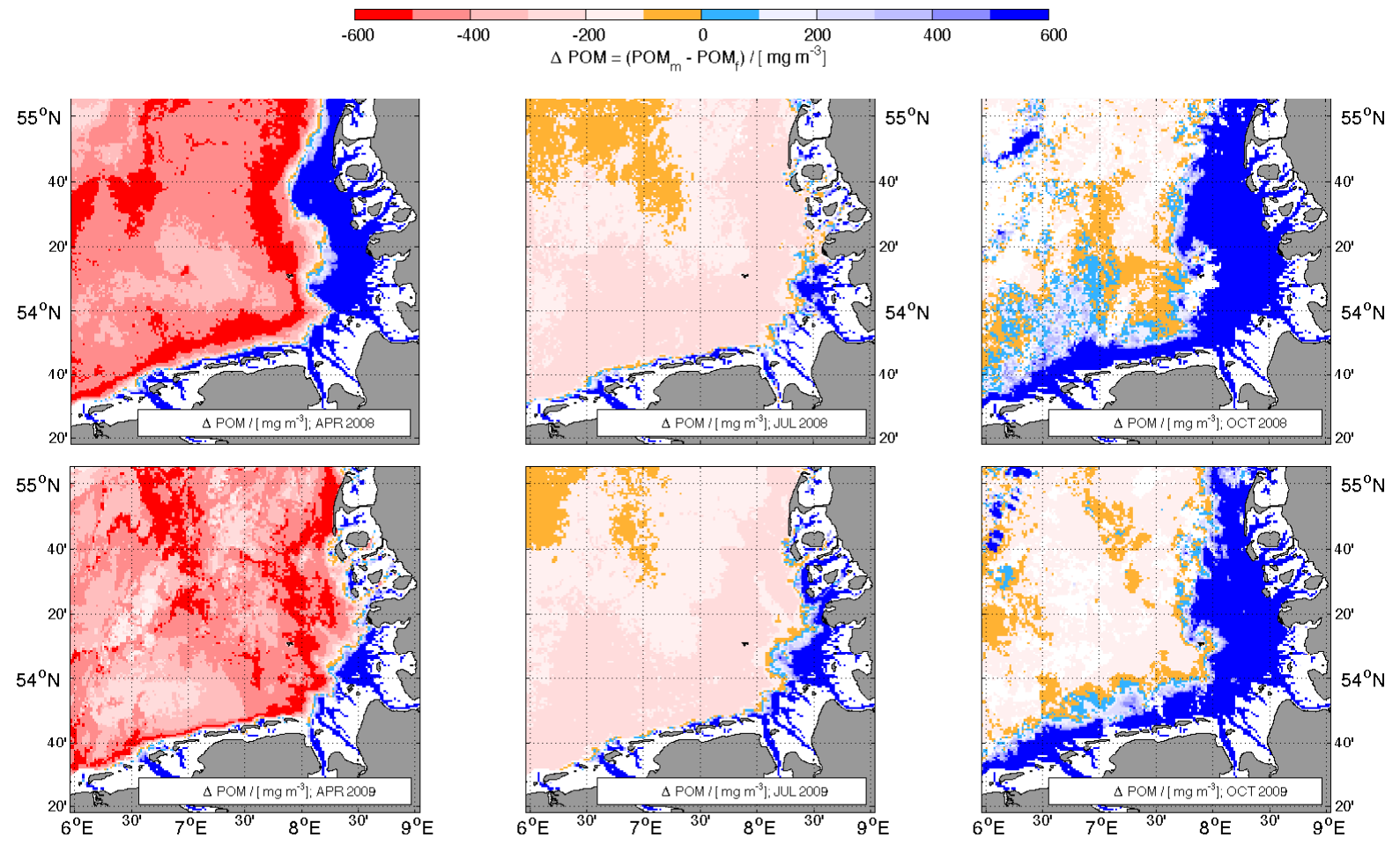

Figure S5: Difference between fresh particluate organic matter $\left(\mathrm{POM}_{f}\right)$ and the fraction that is proportional to particulate inorganic matter concentration (mineral associated $\mathrm{POM}_{m}$ ) for the years 2008 and 2009. The blue color code indicate $\mathrm{POM}_{m}$ concentrations that exceed $\mathrm{POM}_{f}$. The red color code show where $\mathrm{POM}_{f}$ concentrations exceed $\mathrm{POM}_{m}$. The transition from $\mathrm{POM}_{m}>\mathrm{POM}_{f}$ to $\mathrm{POM}_{f}>\mathrm{POM}_{m}$ are explicitly marked orange and cyan $( \pm 100$ $\mathrm{mg} \mathrm{m}^{-3}$ ). These orange/cyan colored areas thus exhibit those coastal ocean regions where $\mathrm{POM}_{f}$ and $\mathrm{POM}_{m}$ approach similar concentrations. 